This is the final peer-reviewed accepted manuscript of:

Formentin, S.M., Zanuttigh, Semi-automatic detection of the overtopping waves and reconstruction of the overtopping flow characteristics at coastal structures

(2019) Coastal Engineering, 152

The final published version is available online at:

https://doi.org/10.1016/j.coastaleng.2019.103533

(C2019. This manuscript version is made available under the Creative Commons AttributionNonCommercial-NoDerivs (CC BY-NC-ND) 4.0 International License

(http://creativecommons.org/licenses/by-nc-nd/4.0/) 


\title{
SEMI-AUTOMATIC DETECTION OF THE OVERTOPPING WAVES AND RECONSTRUCTION OF THE OVERTOPPING FLOW CHARACTERISTICS AT COASTAL STRUCTURES
}

\author{
Sara Mizar Formentin'1, Barbara Zanuttigh²
}

(1) Corresponding author. Research fellow, Department of Civil, Chemical, Environmental and Materials Engineering, University of Bologna, Viale del Risorgimento 2, Bologna 40136, Italy. saramizar.formentin2@unibo.it

(2) Associate professor, Department of Civil, Chemical, Environmental and Materials Engineering, University of Bologna, Viale del Risorgimento 2, Bologna 40136, Italy. barbara.zanuttigh@unibo.it.

\section{Abstract}

This paper proposes a semi-automatic and customizable procedure for the identification of the overtopping waves based on a threshold-down-crossing analysis of the sea surface elevation signals. The procedure can be applied to $2 \mathrm{D}$ experimental and numerical signals, to emerged and submerged structures, with the same accuracy of a human-supervised analysis. The procedure includes an original and innovative algorithm to compare the water level signals at consecutive gauges and couple the waves propagating in between. The coupling algorithm implies a series of original applications of practical relevance, such as: $i$ ) the computation of the wave celerity, which is a crucial parameter for the assessment of the structural stability and the hydraulic vulnerability of the landward area; ii) the estimation of the wave overtopping discharge, which can be obtained by integrating the wave celerities with the surface elevations; iii) the description of the wave overtopping characteristics and their evolution over the structure crest; iv) the evaluation of the volumes lost for percolation in permeable structures. The application to new and literature data and the comparison with well-established formulae prove that the results obtained from the identification and coupling procedures are accurate and reliable.

Keywords: semi-automatic procedure; wave coupling; wave celerity; flow velocity; wave overtopping discharge; individual wave overtopping volumes; probability of overtopping. 


\section{$34 \quad$ Highlights}

35 A new semi-automatic procedure for the identification and coupling of the overtopping waves is 36 presented

37 The accuracy of this new procedure is the same achieved by visual examination of the wave 38 signals time series

39 The procedure allows the calculation of the wave celerities and the estimation of the overtopping 40 discharge

41 The procedure allows to reconstruct the probability distribution of the overtopping volumes

42 The procedure allows for the analysis of the evolution of the overtopping flow characteristics 43 across the structure crest

44 


\section{Introduction}

For design purposes, the identification of the single overtopping events and the analysis of their evolution over the structure crest represent the key information for the assessment of the hydraulic vulnerability of the structures and the stability of the armour layers. Specifically, the accurate identification of the waves is essential for the reconstruction of the statistical distribution of the individual overtopping volumes, which govern the hydrodynamic forces acting on the crests and the landward-side slopes (Van der Meer et al., 2010; Hughes et al., 2012).

The more recent automatic procedures for the reconstruction of the individual overtopping volumes are based on the zero up-crossing or down-crossing analysis of the sea surface elevation signals at weigh cells (Victor, 2012, later modified by Platteeuw, 2015; Molines et al. 2019) or at resistant gauges (Nørgaard et al., 2014; Hughes, 2015; Hughes and Thornton, 2016). Many of these procedures seem to be affected by unaffordable inaccuracy in comparison with the manually supervised analysis of the discharge time series (Hughes, 2015).

None of these procedures are scoped to identify the waves at consecutive gauges and couple the waves travelling along the structure crest. The computation of the wave time lags from the off-shore to the in-shore gauge would allow the derivation of the wave front velocity propagation, i.e. the wave celerity, which may be used as an estimator of the flow velocity (Schüttrumpf and Oumeraci, 2005; Lykke Andersen et al., 2011) and can be integrated with the water levels to derive the instantaneous and average overtopping discharges. Coupling the single overtopping waves would also allow the reconstruction of the evolution of the wave shapes, which is fundamental for characterizing the wave asymmetries (a.o., Peng et al., 2009; Chella et al., 2015) or for estimating the volumes lost for percolation over the crest of permeable structures (Zanuttigh and Lamberti, 2006).

Yet, as far as known, an automatic procedure for coupling the overtopping events, which is of wide applicability and which can guarantee high standards of confidence, is missing. A first attempt was made by Zanuttigh and Lamberti (2006), whose procedure was not applicable to all crest level conditions and was strongly affected by the selection of appropriate threshold values.

This contribution describes a new, advanced and versatile procedure for the identification of the overtopping waves specifically developed to overcome the problems of the automatic detection, in order to reproduce the number of the overtopping waves as they would have been recognized by a manual analysis of the wave signal (see Hughes et al., 2015; 2016). The procedure has been recently presented in Formentin and Zanuttigh $(2018, b)$ through a preliminary application to a numerical database consisting of wave overtopping at smooth dikes. In the present work, the procedure is fully validated against a new set of experiments recently carried out by the authors (Zanuttigh and Formentin, 2018) and a set of original applications of practical interest are presented with reference to a wide laboratory dataset.

The procedure is conceived to elaborate water level time signals and reconstruct the shape parameters of the overtopping waves (crest and trough elevations and durations), but it can process any kind of oscillatory signal in the time domain. The waves are detected through the 
implementation of a threshold-down-crossing algorithm, where the 2 threshold values vary with the wave characteristics, the structural parameters, and the scale of the data. The setting of the thresholds can be customized by the user to achieve the desired level of accuracy in the identification of the overtopping events. A second algorithm can couple the waves travelling over the structure crest so that the wave celerity, the wave overtopping discharge, the overtopping volumes can be estimated. The procedure can deal with both regular and irregular 2D waves propagating perpendicularly towards the structures. The wave identification requires as input a unique signal recorded at one gauge, while the wave coupling requires at least 2 signals recorded at 2 consecutive gauges.

Section 2 presents a short overview of the datasets used to illustrate, calibrate and validate this new procedure. In particular, the new set of overtopping experiments at dikes, used for the validation of the procedure and the presentation of its results, is introduced. The algorithm and the working principle of the procedure are described in Section 3 by steps, including the validation of the procedure and the assessment of the validity of the adopted criteria. Sections 4 and 5 propose a set of applications to smooth and rubble mound structures, respectively. The conclusions on the work are drawn in Section 6.

\section{Experimental and numerical datasets}

This Section presents and describes the 5 groups of tests that are used to describe, validate and illustrate the application fields of the procedure. The ranges of variability of the hydraulic and structural parameters relative to these datasets represent therefore the field of applicability on which the procedure has been tested so far. Table 1 proposes a summary of the 5 datasets, while their details are given in the Sub-section 2.1 to 2.5 .

All the datasets considered in this work consist of overtopping tests at structures (smooth dikes or rubble mound breakwater) which are characterized by a similar, simple trapezoidal crosssection. Figure 1 provides a schematic layout of the typical cross-section, with reference to the main symbols adopted hereinafter to describe the geometrical parameters of the structures and the working principle of the procedure:

- the structure off-shore and in-shore slopes, $\alpha_{\text {off }}$ and $\alpha_{\text {in; }}$;

- the water depth before the structure $w d$ and structure crest freeboard $R_{c}$;

- the structure crest width $G_{c}$;

- the position of the 2 generic "wave gauges" (wgs, hereinafter) for the registration of the water level signals at the structure crest to be processed with the procedure, and their distance diswg; the term "wg" can refer to resistant wave gauges, pressure transducers, Acoustic Doppler Velocimeters, etc., according to the instruments used in the different experiments;

- the water depth, or the free surface elevation, $h$ measured at the $2 \mathrm{wgs}, h_{1}$ and $h_{2}$, respectively. 
Table 1. Summary and characteristics of the 5 datasets of tests on wave overtopping mentioned throughout the manuscript and involved in the application of the new procedure.

\begin{tabular}{|c|c|c|c|c|c|c|}
\hline $\begin{array}{c}\text { Dataset } \\
\text { Label }\end{array}$ & $\begin{array}{l}\text { Number } \\
\text { of tests }\end{array}$ & $\begin{array}{l}\text { Description of } \\
\text { the tests }\end{array}$ & $\begin{array}{c}\text { Freeboard } \\
\text { range } R_{c} / H_{s}\end{array}$ & $\begin{array}{c}\text { Slope } \\
\cot \left(\alpha_{\text {off }}\right)\end{array}$ & $\begin{array}{c}\text { Employment of } \\
\text { the dataset }\end{array}$ & Reference \\
\hline UB-num & 94 & $\begin{array}{l}\text { 2D numerical } \\
\text { tests at smooth } \\
\text { dikes }\end{array}$ & $+-1.5 ; 1.5]$ & $4 ; 6$ & $\begin{array}{c}\text { Description of the } \\
\text { procedure } \\
\text { (Sec.s 3.1, 3.2) }\end{array}$ & $\begin{array}{l}\text { Formentin } \\
\text { and } \\
\text { Zanuttigh } \\
(2018, a)\end{array}$ \\
\hline HT & 8 & $\begin{array}{l}\text { 2D and 3D } \\
\text { experiments at } \\
\text { smooth dikes }\end{array}$ & {$[0.319 ; 1.064]$} & $3 ; 6$ & $\begin{array}{c}\text { Validation of the } \\
\text { identification step } \\
\text { (Sec. } 3.3 .1)\end{array}$ & $\begin{array}{c}\text { Hughes and } \\
\text { Thornton } \\
(2016)\end{array}$ \\
\hline HS & 3 & $\begin{array}{l}\text { 2D experiments } \\
\text { on levees }\end{array}$ & $\begin{array}{c}{[-0.430 ;-} \\
0.121]\end{array}$ & 4.25 & $\begin{array}{l}\text { Validation of } \\
\text { coupling step } \\
\text { (Sec. 3.3.1) }\end{array}$ & $\begin{array}{l}\text { Hughes and } \\
\text { Shaw (2011) }\end{array}$ \\
\hline UB-exp & 54 & $\begin{array}{l}\text { 2D experiments } \\
\text { at smooth dikes }\end{array}$ & $0 ; 0.5 ; 1$ & $2 ; 4$ & $\begin{array}{c}\text { Results and } \\
\text { applications of } \\
\text { the procedure } \\
\text { (Sec. 4) }\end{array}$ & $\begin{array}{l}\text { Zanuttigh } \\
\text { and } \\
\text { Formentin } \\
(2018)\end{array}$ \\
\hline AAU & 33 & $\begin{array}{c}\text { 3D experiments } \\
\text { tests at } \\
\text { permeable } \\
\text { breakwaters }\end{array}$ & {$[-1.59 ; 0.49]$} & 2 & $\begin{array}{l}\text { Results and } \\
\text { applications of } \\
\text { the procedure } \\
\text { (Sec. } 5)\end{array}$ & $\begin{array}{c}\text { Kramer et al. } \\
\text { (2005) }\end{array}$ \\
\hline
\end{tabular}

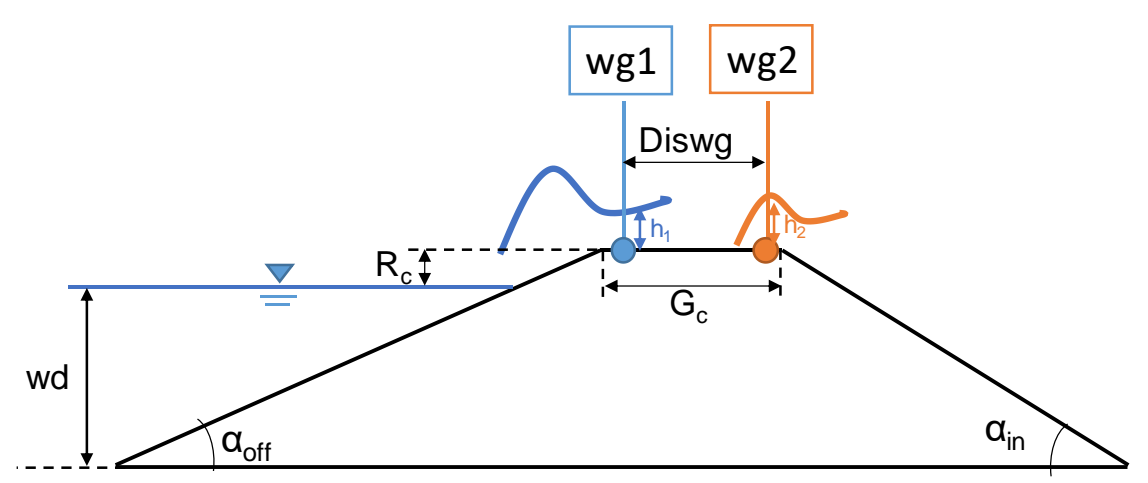

Figure 1 - Scheme of a dike for the application of the new procedure, including 2 wgs at the offshore (wg1) and in-shore (wg2) edges of the crest.

\subsection{Dataset “UB-num”}

The numerical database of tests on wave overtopping against smooth dikes collected by Formentin et al. (2014) and extended by Formentin and Zanuttigh (2018, a), "UB-num", hereinafter, includes 94 tests on structures at various crest freeboards, with $R_{d} / H_{s}$ ranging from 
-1.5 to $+1.5,2$ off-shore slopes $\cot \left(\alpha_{\text {off }}\right)=4$ and 6 and fixed in-shore slope $\cot \left(\alpha_{\text {in }}\right)=3$ and fixed crest width $G_{c}=0.3 \mathrm{~m}$. The wave attacks included 2 target wave heights $H_{s}=0.1$ and $0.2 \mathrm{~m}$ and wave steepnesses $H_{s} / L_{m-1,0}$ in the range $0.02-0.05$, where $L_{m-1,0}$ is the wave length computed on the spectral wave period $T_{m-1,0}$. The simulations were carried out with the $\mathrm{IH}-2 \mathrm{VOF}$ code developed by the University of Cantabria (Lara et al., 2011) and the summary of the tested conditions is given in Table 2.

For all the tests, 2 numerical wave gauges (wgs), namely wg1 and wg2, were placed in proximity of the off-shore and in-shore edges of the crest width, at the distance diswg=0.27 $\mathrm{m}$. wg 1 and wg2 provided the time records of the free-surface elevations $(h,[\mathrm{~m}])$ and the cross-shore flow velocities $(u,[\mathrm{~m} / \mathrm{s}])$. These records can be processed by the procedure and were used indeed for the calibration of its parameters (Sub-sections 3.1 and 3.2) and in part for the validation of its results (Sub-section 3.3). For all the simulations, the adopted sampling frequency (sf) at wg 1 and $w g 2$ was $s f=20 \mathrm{~Hz}$.

Table 2. Summary of the tested conditions of the numerical database collected by Formentin and Zanuttigh $(2018, a)$. For all the tests, $G_{c}=0.3 \mathrm{~m}$, diswg $=0.27$ and $\cot \left(\alpha_{i n}\right)=3$. The water depth $w d=0.85-R_{c} . s f=20 \mathrm{~Hz}$.

\begin{tabular}{|c|c|c|c|c|c|c|c|c|}
\hline$R_{c} / H_{s}$ & -1.5 & -1 & -0.5 & -0.2 & 0 & +0.5 & +1 & +1.5 \\
\hline$H_{s} / L_{m-1,0}[\%]$ & $2 ; 3$ & $2 ; 3 ; 4$ & $2 ; 3 ; 5$ & 2 & $2 ; 3 ; 4 ; 5$ & $2 ; 3 ; 4$ & $2 ; 3 ; 4$ & 3 \\
\hline$H_{s}[\mathrm{~m}]$ & $0.1 ; 0.2$ & $0.1 ; 0.2$ & $0.1 ; 0.2$ & 0.2 & $0.1 ; 0.2$ & $0.1 ; 0.2$ & 0.2 & 0.2 \\
\hline $\cot \left(\alpha_{\text {off }}\right)$ & $4 ; 6$ & $4 ; 6$ & $4 ; 6$ & $4 ; 6$ & $4 ; 6$ & $4 ; 6$ & $4 ; 6$ & $4 ; 6$ \\
\hline Tot. \# & 12 & 18 & 18 & 2 & 20 & 16 & 6 & 2 \\
\hline
\end{tabular}

\subsection{Dataset "HT"}

The FlowDike 1 and FlowDike 2 experiments on wave overtopping and run-up were conducted in the wave basin at the Danish Hydraulic Institute in Hørsholm, DK (Lorke et al., 2009 and 2010). These experiments involved 2D and 3D wave attacks against smooth dikes characterized by 2 $G_{c}$ values ( 0.6 and $0.7 \mathrm{~m}$, model scale values) and $2 \cot \left(\alpha_{\text {off }}\right)$ values ( 3 and 6 , respectively FlowDike 1 and FlowDike 2). A subset of 8 irregular 2D tests at emerged freeboard $\left(R_{d} H_{s}>0\right)$ belonging to the FlowDike experiments were selected by Hughes and Thornton (2016) and elaborated to identify the individual wave overtopping waves based on a human-supervised analysis of the time series of the overtopping discharge. The identification step of the new procedure proposed in this contribution has been applied to the same 8 tests and the results are compared to the achievements of Hughes and Thornton (2016) for validation (Sub-section 3.3.1). The characteristics of the 8 tests are resumed in Table 3, where: the subscript "HT" means "Hughes and Thornton, 2016" and refers to the quantities obtained by the application of the procedure by Hughes and Thornton, 2016; Nw = number of waves; $\mathrm{V}=$ volumes; Pow = "probability of overtopping"; Man = "recognized by manual detection (human supervised)"; Auto = "recognized by automatic detection"; Total = auto+man. In Table 3 the symbol $H_{m o}$ is used to refer to the spectral wave height calculated at the structure toe as reported in Hughes and Thornton (2018). 
Table 3. Summary of the 8 selected experiments and corresponding wave volume determination performed by the supervised procedure by Hughes and Thornton (2016) and by the new procedure. The columns to be compared each other are shaded with the same colour.

\begin{tabular}{|c|c|c|c|c|c|c|c|c|c|c|c|c|}
\hline \multirow[b]{2}{*}{ Test ID } & \multicolumn{4}{|c|}{ Tests parameters } & \multicolumn{5}{|c|}{ Hughes and Thornton (2016) procedure } & \multicolumn{3}{|c|}{ New procedure } \\
\hline & $\begin{array}{l}\mathrm{H}_{\mathrm{m0}} \\
{[\mathrm{m}]}\end{array}$ & $\begin{array}{c}T_{m-1,0} \\
{[s]}\end{array}$ & $\begin{array}{c}\mathrm{R}_{\mathrm{c}} / \mathrm{H}_{\mathrm{s}} \\
{[-]}\end{array}$ & $\begin{array}{l}\text { Nw } \\
{[-]}\end{array}$ & $\begin{array}{l}\text { Auto } \\
V_{H T}\end{array}$ & $\begin{array}{l}\text { Man } \\
V_{H T}\end{array}$ & $\begin{array}{l}\text { Total } \\
\mathrm{V}_{\mathrm{HT}}\end{array}$ & $\begin{array}{l}\text { (Auto } \mathrm{V}_{\mathrm{HT}} \text { )/ } \\
\text { (Total } \mathrm{V}_{\mathrm{HT}} \text { ) }\end{array}$ & Pow & $\begin{array}{c}\text { Auto } \\
\mathrm{V}\end{array}$ & $\begin{array}{c}\text { (Auto V)/ } \\
\text { (Total } \mathrm{V}_{\mathrm{HT}} \text { ) }\end{array}$ & Pow \\
\hline 0198 & 0.103 & 1.619 & 0.971 & 1180 & 486 & 177 & 663 & $73 \%$ & $56 \%$ & 636 & $96 \%$ & $54 \%$ \\
\hline 0199 & 0.094 & 1.164 & 1.064 & 1102 & 211 & 235 & 446 & $47 \%$ & $40 \%$ & 356 & $80 \%$ & $31 \%$ \\
\hline 0200 & 0.15 & 1.96 & 0.667 & 1276 & 453 & 361 & 814 & $56 \%$ & $64 \%$ & 839 & $103 \%$ & $66 \%$ \\
\hline 0201 & 0.148 & 1.379 & 0.376 & 1150 & 254 & 493 & 747 & $34 \%$ & $65 \%$ & 680 & $91 \%$ & $59 \%$ \\
\hline 0451 & 0.09 & 1.555 & 0.556 & 1097 & 535 & 46 & 581 & $92 \%$ & $53 \%$ & 621 & $107 \%$ & $57 \%$ \\
\hline 0453 & 0.122 & 1.663 & 0.410 & 1120 & 726 & 142 & 868 & $84 \%$ & $78 \%$ & 931 & $107 \%$ & $83 \%$ \\
\hline 0456 & 0.157 & 1.936 & 0.319 & 1093 & 617 & 275 & 892 & $69 \%$ & $82 \%$ & 904 & $101 \%$ & $83 \%$ \\
\hline 0457 & 0.141 & 1.373 & 0.355 & 1116 & 521 & 267 & 788 & $66 \%$ & $71 \%$ & 794 & $101 \%$ & $71 \%$ \\
\hline
\end{tabular}

\subsection{Dataset "HS"}

To validate the coupling step of the new procedure, 3 tests were selected from a set of experiments on wave overtopping carried out against a trapezoidal levee in 1:25 scale at the Coastal and Hydraulics Laboratory (CHL) in Vicksburg, MS (Hughes and Shaw, 2011). All the experiments (HS, hereinafter) were performed in submerged conditions (negative freeboard of the levee crest) to investigate the combined effects of the storm surge overflow and the wave overtopping. $2 \mathrm{wgs}$, placed over the crest of the levee at a distance of $62 \mathrm{~cm}$ (diswg=0.62 $\mathrm{m}$ ), were used to measure the flow thickness $h$ over the levee and the pressure, and a laser Doppler velocimeter (ADV) was installed in correspondence of the second wg to measure the horizontal component of the flow velocity $u$. The full description of the experiments is given in Hughes and Shaw (2011), while the main hydraulic parameters of the 3 selected tests are reported in model scale units in Table 4. Only 3 tests were used for the application of the procedure because these are the only ones for which the records of $h$ at the 2 wgs were available. In Table $4, H_{m o}$ refers to the spectral wave height at the structure toe as reported by Hughes and Shaw (2018) while sf is the sample frequency adopted to record the free-surface elevations and velocities. $u_{2 \%}$ and $c_{\text {mean }}$ are, respectively, the values of the flow velocities measured exceeded by the $2 \%$ of the incoming waves and the mean wave celerities computed with the coupling step of the procedure.

Table 4. Comparison among the lab measurements of the horizontal flow velocity $\left(u_{2} \%\right)$ and the wave celerities ( $\left.c_{\text {mean }}\right)$ derived from the new procedure for 3 tests by Hughes and Shaw (2011).

\begin{tabular}{|c|c|c|c|c|c|c|c|c|}
\hline Test ID & $H_{m 0}[\mathrm{~m}]$ & $T_{p}[\mathrm{~s}]$ & $R_{c}[\mathrm{~m}]$ & $R_{c} / H_{m 0}$ & $H_{m o} /\left|R_{c}\right|$ & sf $[\mathrm{Hz}]$ & $\begin{array}{c}\text { Lab data } \\
u_{2 \%}[\mathrm{~m} / \mathrm{s}]\end{array}$ & $\begin{array}{c}\text { New procedure } \\
C_{m e a n}[\mathrm{~m} / \mathrm{s}]\end{array}$ \\
\hline R14 & 0.071 & 2.09 & -0.0110 & -0.155 & 6.45 & 100 & 0.800 & 0.895 \\
\hline R18 & 0.100 & 2.77 & -0.043 & -0.430 & 2.33 & 100 & 1.113 & 1.268 \\
\hline R109 & 0.099 & 2.73 & -0.012 & -0.121 & 8.25 & 50 & 0.722 & 0.729 \\
\hline
\end{tabular}




\subsection{Dataset “UB-exp”}

A set of new experimental tests of wave overtopping was recently carried out by the authors in the wave flume of the Hydraulics Laboratory of the University of Bologna (Zanuttigh and Formentin, 2018), UB-exp, hereinafter. The wave flume was equipped with an overtopping tank for the storage of the overtopping volumes and a recirculation system consisting of a pump and a flowmeter. The experiments consisted of irregular waves at dikes (54 tests) and dikes with a crown wall and a parapet (91 tests) at zero or positive freeboards $\left(0 \leq R_{c} / H_{s} \leq 1\right)$. The procedure was applied to the 54 tests on dikes without walls exclusively. The selected structures schematized in Figure 2 - consist of 4 dike configurations obtained by combining 2 crest widths $\left(G_{c}=0.3\right.$ and $\left.0.15 \mathrm{~m}\right)$ and 2 slopes $\left(\cot \left(\alpha_{\text {off }}\right)=2\right.$ and 4$)$. The height of the dike crest was kept constant and equal to $0.35 \mathrm{~m}$ (with respect to the bottom of the wave flume) and the different freeboards were realized by varying the water depth $w d$ from 0.29 to $0.35 \mathrm{~m}$. For each dike, 6 irregular wave attacks were performed, combining $3 H_{s}(0.04,0.05$ and $0.06 \mathrm{~m})$ and $2 H_{s} / L_{m-1,0}$ ( $3 \%$ and $4 \%$ ). The matrix of the tested conditions is given in Table 5.

All the dikes were equipped with 3 Ultrasonic Doppler Velocity Profilers (UVPs), named "D4", "D5" and "D6", characterized by $s f=50 \mathrm{~Hz}$ and placed consecutively along the structure crest from the off-shore edge to the in-shore edge, as displayed in Figure 2. These UVPs were used to derive the time series of the vertical profiles of the flow velocities $(u,[\mathrm{~m} / \mathrm{s}])$ and track the free surface elevation $(h,[\mathrm{~m}])$ at D4, D5 and D6, based on the following methodologies.

- $u$. At each time step, the UVPs measured the horizontal component of the flow velocity ( $u$, $[\mathrm{m} / \mathrm{s}]$ ) at 40 gates linearly spaced along the direction of the acoustic impulse. The range of the impulse was set approximately $10 \mathrm{~cm}$ for each UVP, i.e. a distance which should be sufficient to sweep the whole water column from the dike crest to the free surface also in the case of the largest waves $\left(H_{s}=0.06 \mathrm{~m}\right)$. By dividing the range of the impulse $(10 \mathrm{~cm})$ by the number of gates $(40)$, the spatial resolution of $\approx 0.0025 \mathrm{~m}$ is obtained for the vertical profiles of $u$.

- $h$. At each time step and at the same 40 gates along the direction of the sonic impulse, the UVPs recorded also the values of the echo $(\mathrm{dB})$. In correspondence of the free surface, the acoustic impulse undergoes a strong reflection, which determines a sharp peak of the echo value. The time series of the free-surfaces at each UVP have been reconstructed based on the position of the peaks in the instantaneous vertical profiles of the echo.

The time series of $h$ at D4 and D6 were elaborated with the new procedure to detect and couple the individual overtopping volumes. In this application, D4 and D6 represent therefore "wg1" and "wg2", respectively. The distances between D4 and D6, diswg, are respectively equal to $0.09 \mathrm{~m}$ and $0.243 \mathrm{~m}$ for $G_{c}=0.15 \mathrm{~m}$ and $G_{c}=0.30 \mathrm{~m}$, see Table 5 .

The time series of $u$ were elaborated to get the statistics of the overtopping flow velocities at the off-shore edge $(\approx D 4)$ and to validate the coupling step of the procedure (see Sub-section 3.4.1), but were not directly elaborated by the procedure itself. 

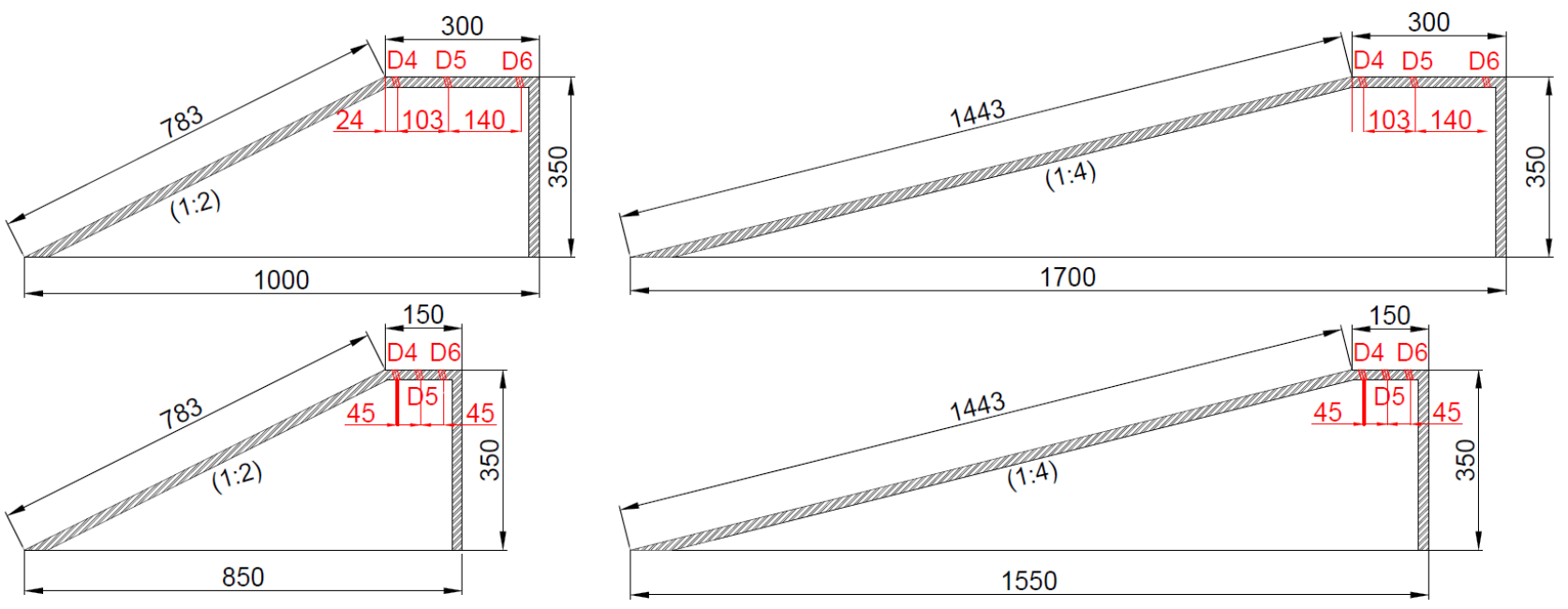

Figure 2 - Scheme of the 4 dike configurations tested in the Laboratory of Hydraulics at the University of Bologna (Zanuttigh and Formentin, 2018). The positions of the 3 UVPs (D4, D5, D6) installed across the dike crest are marked with red colour. The measures are in $\mathrm{mm}$.

Table 5. Summary of the tested conditions characterizing the 54 experiments of wave overtopping at dikes selected from the new database by Zanuttigh and Formentin (2018). For all the tests, $s f=50 \mathrm{~Hz}$.

\begin{tabular}{|c|c|c|c|}
\hline$R_{c} / H_{s}$ & 0 & +0.5 & +1 \\
\hline$H_{s} / L_{m-1,0}[\%]$ & $3 ; 4$ & $3 ; 4$ & $3 ; 4$ \\
\hline$H_{s}[\mathrm{~m}]$ & $0.04 ; 0.05 ; 0.06$ & $0.04 ; 0.05 ; 0.06$ & $0.04 ; 0.05 ; 0.06$ \\
\hline$w d[\mathrm{~m}]$ & 0.35 & {$[0.32 ; 0.33]$} & {$[0.29 ; 0.31]$} \\
\hline $\cot \left(\alpha_{\text {off }}\right)$ & $2 ; 4$ & $2 ; 4$ & $2 ; 4$ \\
\hline$G_{c}[\mathrm{~m}]$ & $0.15 ; 0.30$ & $0.15 ; 0.30$ & $0.15 ; 0.30$ \\
\hline diswg $[\mathrm{m}]$ & 0.09 for $G_{c}=0.15 \mathrm{~m} ; 0.243$ for $G_{c}=0.30 \mathrm{~m}$ \\
\hline Tot. \# & 24 & 18 & 18 \\
\hline
\end{tabular}

\subsection{Dataset "AAU"}

The dataset of experimental tests performed in the shallow water basin at the Aalborg University (Kramer et al., 2005; Zanuttigh and Lamberti, 2006) consists of 33 perpendicular, regular and irregular wave attacks against 2 permeable structures with a gap in between, was selected. The main hydraulic and structural parameters characterizing the 33 tests selected (dataset "AAU") are summarized in Table 6, while the top view of the structures is here reported in Figure 3. 


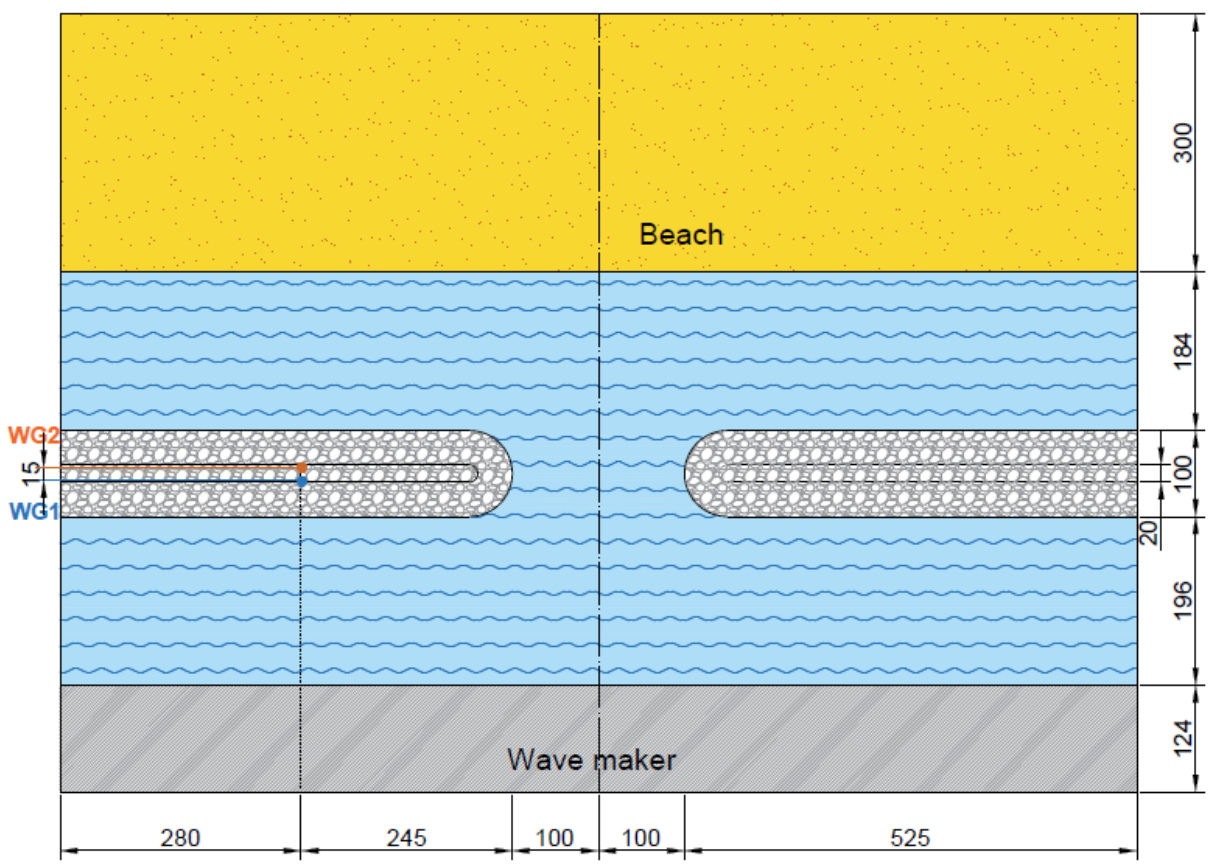

248 Figure 3 - Top view of the permeable structures with a gap in between used for the experiments 249 at the Aalborg University by Kramer et al., 2005 (dataset AAU). Narrow berm configuration. The 250 positions of wg1 and wg2 are represented by filled-in circles. Measures in centimeters.

252 Table 6. Summary of the hydraulic and structural parameters characterizing the 33 tests selected 253 from the database of Kramer et al. (2005) for the assessment of the accuracy of the new 254 procedure. Scale 1:20.

\begin{tabular}{|c|c|c|}
\hline Parameter & values or range & description of the parameter \\
\hline$R_{c}[\mathrm{~m}]$ & $-0.07,0$ and 0.03 & crest freeboard \\
\hline$w d[\mathrm{~m}]$ & $0.27,0.20$ and 0.17 & water depth at the structure toe \\
\hline$H_{s}[\mathrm{~m}]$ & {$[0.020 ; 0.129]$} & significant wave heights at the structure toe \\
\hline$T_{p}[\mathrm{~s}]$ & {$[0.74 ; 1.97]$} & peak wave period \\
\hline$G_{c}[\mathrm{~m}]$ & 0.2 and 0.6 & width of the structure crest \\
\hline $\cot \left(\alpha_{o f f}\right)$ & 2 & cotangent of the seaward slope \\
\hline $\cot \left(\alpha_{i n}\right)$ & 2 & length of each barrier (2 barriers at all) \\
\hline$L_{b}[\mathrm{~m}]$ & 5.05 & length of the gap between the two barriers \\
\hline$L_{g a p}[\mathrm{~m}]$ & 2.40 & sample frequency adopted for the experiments \\
\hline$s f[\mathrm{~Hz}]$ & 40 & $\begin{array}{c}\text { distance between the experimental gauges } \\
\text { (wg1 and wg2) placed over the structure crest }\end{array}$ \\
\hline diswg $[\mathrm{m}]$ & $\begin{array}{c}\left.0.15 \text { (for } G_{c}=0.2\right) \\
\left.\text { and } 0.40 \text { (for } G_{c}=0.6\right)\end{array}$ &
\end{tabular}




\section{3. Description and validation of the procedure}

256 The new procedure has been developed to i) identify the single overtopping waves from the 257 signals acquired at wave gauges (wgs) over the structure crest and ii) to couple 2 (or more) wave 258 signals registered at consecutive gauges, namely wg1 and wg2. The procedure can be applied 259 to both physical and numerical models, emerged and low-crested structures and to any structure 260 surface type (i.e. smooth or rough). It can process any kind of oscillatory signal in the time 261 domain, i.e. not exclusively water surface ( $h$, hereinafter) signals but also, e.g., wave overtopping 262 discharge ( $q$, hereinafter) time series.

263 The whole procedure is structured into 2 sequential steps, i.e. the identification of the waves and 264 the coupling. The first step can be applied to one or more $h$-signals (or $q$-signals) registered at 265 one or more wgs and it is independent of the second one. The second step instead requires at 266 least two $h$-signals at two wgs, which must be previously processed by the first step. The 267 conceptual layout of the full procedure is schematized in Figure 4.

268 The description of the wave identification and wave coupling steps is given in the Sub-sections 2693.1 and 3.2 respectively. The validation of the procedure and the assessment of the adequacy 270 of the adopted criteria are respectively provided in Sub-sections 3.3 and 3.4. 

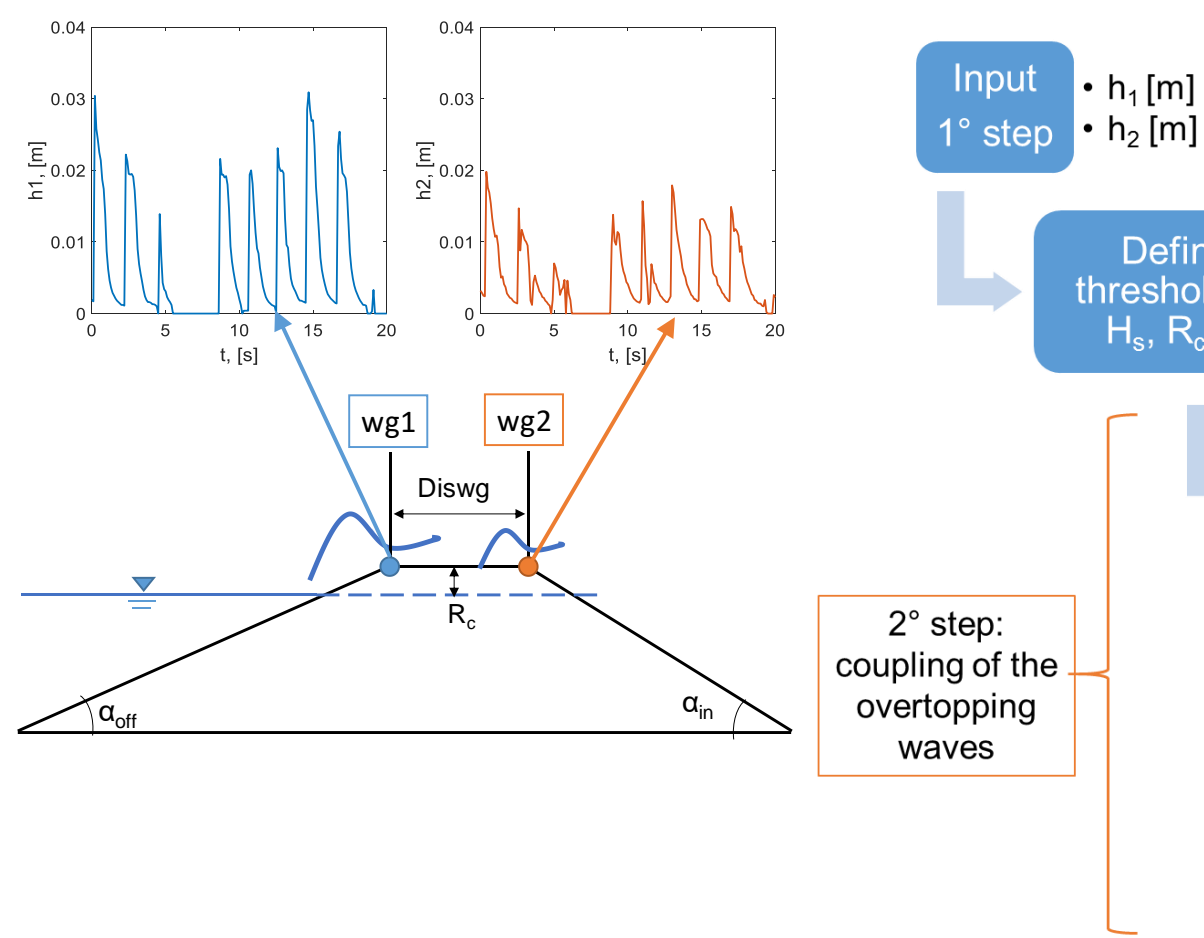

Definition of the thresholds (based on $H_{s}, R_{c}$ and diswg)

- $\mathrm{u}_{\text {th1 }}$ and $\mathrm{I}_{\mathrm{th} 1}[\mathrm{~m}]$ - $\mathrm{u}_{\mathrm{th} 2}$ and $\mathrm{I}_{\mathrm{th} 2}[\mathrm{~m}]$

$$
\begin{array}{cc}
\text { Output } 1^{\circ} \text { step } & \cdot \mathrm{Dc}_{1}[\mathrm{~s}], \mathrm{Zcr}_{1} \text {, and } \mathrm{Ztr}_{1}[\mathrm{~m}] \\
\text { Input } 2^{\circ} \text { step } & \cdot \mathrm{Dc}_{2}[\mathrm{~s}], \mathrm{Zcr}_{2} \text {, and } \mathrm{Ztr}_{2}[\mathrm{~m}]
\end{array}
$$
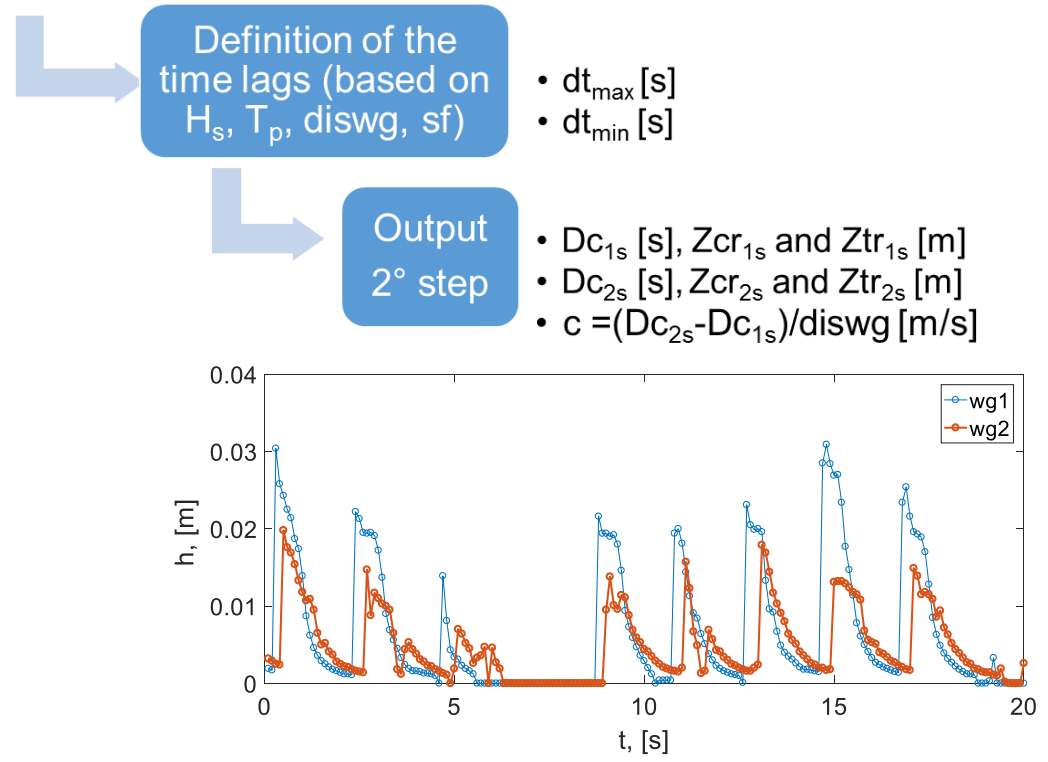

Figure 4 - Conceptual layout of the new procedure for the identification ( $1^{\text {st }}$ step) and the coupling $\left(2^{\text {nd }}\right.$ step) of the single wave overtopping 274 waves. 


\subsection{Wave identification}

The first step of the procedure is the wave identification algorithm, that is based on a time-domain threshold-down-crossing analysis (tdc, hereinafter) of the sea surface elevation $h$. The algorithm takes as input the time series of $h$-signals registered at one or more wgs and provides as outputs the time-ordered sequence of specific wave overtopping events. Each event can be described by the crest and trough wave heights (Zcr and $\mathrm{Ztr}$ ) and the instants of zero-down-crossing (Dc). 2 consecutive instants of tdc, namely $D c(i-1)$ and $D c(i)$, define the period [Dc(i)-Dc(i-1)], the crest $\mathrm{Zcr}(\mathrm{i})$ and the trough $\mathrm{Ztr}(\mathrm{i})$ elevations of the $\mathrm{i}$-th overtopping event. The procedure provides also the records of the instants of occurrence of Zcr and Ztr, named respectively Icr and Itr.

As a reference to the mentioned symbols, Figure 5 provides an example of a sea surface elevation signal $(h)$ registered at $w g 1$ and processed with the new procedure. The signal in this Figure refers to a numerical test (dataset UB-num) of wave overtopping at a smooth dike $\left(G_{c}=0.3 \mathrm{~m}, \cot \left(\alpha_{\text {off }}\right)=4, \cot \left(\alpha_{\text {in }}\right)=3\right)$ in emerged conditions $\left(R_{c} / H_{s}=0.5\right)$ and subjected to a perpendicular wave attack $\left(H_{s}=0.1 \mathrm{~m}, T_{m-1,0}=2.2 \mathrm{~s}\right)$.

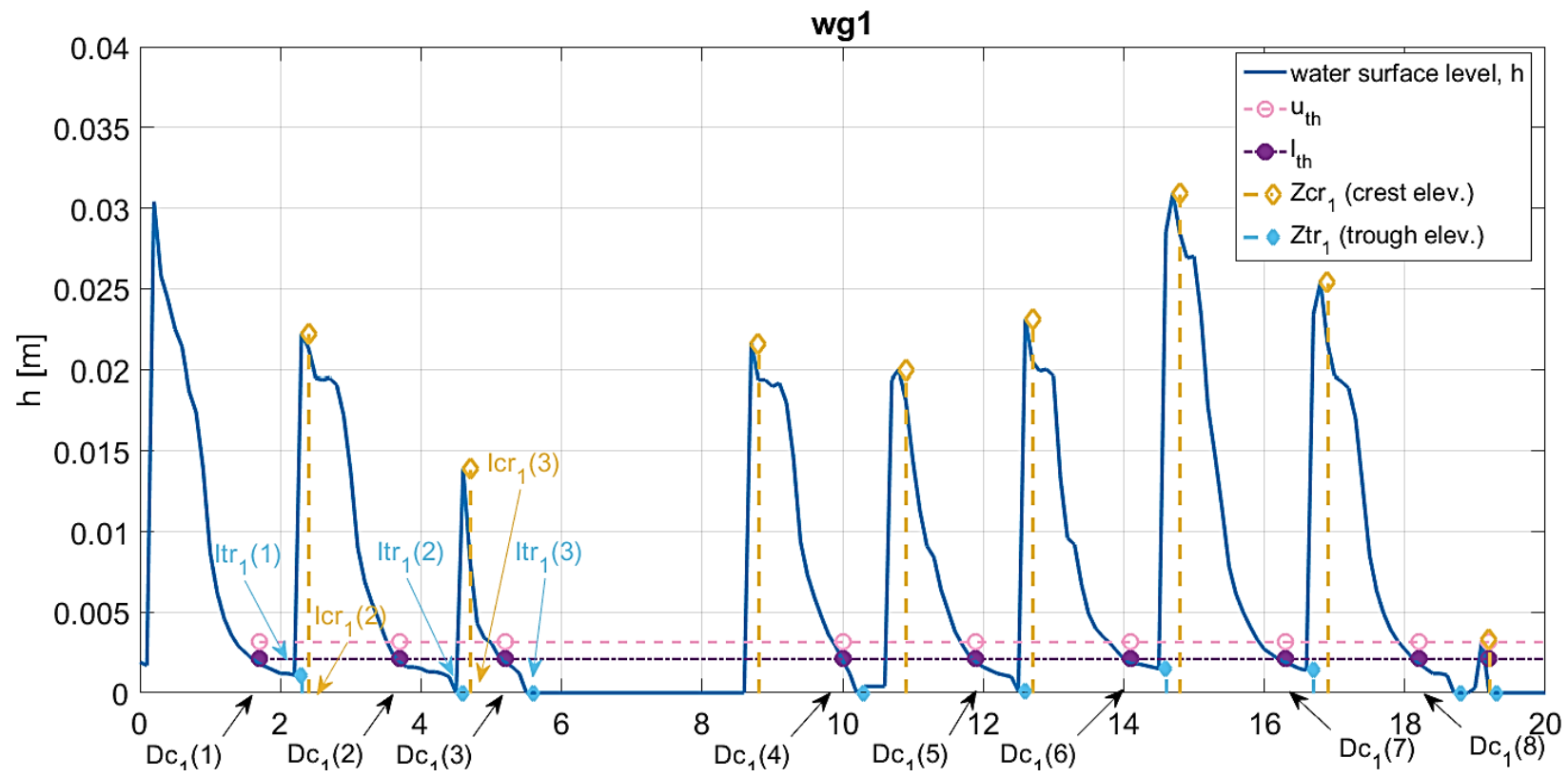

Figure 5 - Example of a sea surface elevation signal $(h)$ registered at $w g 1$ and processed with the new procedure. Data belonging to the example numerical test (UB-num dataset).

The tdc algorithm for the wave identification depends on the definition of a threshold value of $h$ representing the zero-control-value of the sea surface level. When $h$ down-crosses this threshold value, a single event is identified. The value of this threshold, which is going to be referred as "lower threshold" $I_{\text {th }}$ hereinafter, may be 0 (i.e. $I_{\text {th }}=0 \mathrm{~m}$ ) or a different - positive or negative value, e.g. the still water level, depending on the nature of the signal itself. In Fig. $5, I_{\text {th }}$ is represented by the filled-in circles and is $>0$ to account for the water layer over the crest. 
To better understand the procedure and its parameters, the different characteristics of the flow depth over the structure crest depending on the frequent or rare overtopping conditions should be observed. In case of rare overtopping (see the example at $R_{d} / H_{s}=1$ in Fig. 6-a), the sea surface elevation shows usually some bursts of small amplitude and almost instantaneous duration, which are signal noises or irregularities that typically precede or follow the waves and are due to the crest friction and/or wave breaking. The presence of these bursts increases with increasing $R_{d} / H_{s}$ and with the structure roughness. Especially for permeable structures, the bursts are more frequent with increasing diswg (i.e. at wg2), since the water percolates in the mound (see Section 5.2). These irregularities should be discarded in the identification step, as they will also lead to a spurious coupling (see Sub-section 3.2). In case of frequent overtopping, the flow depths over the crest are larger and the wave events are instead well-defined (Fig. 6-b), resulting in a more regular signal.
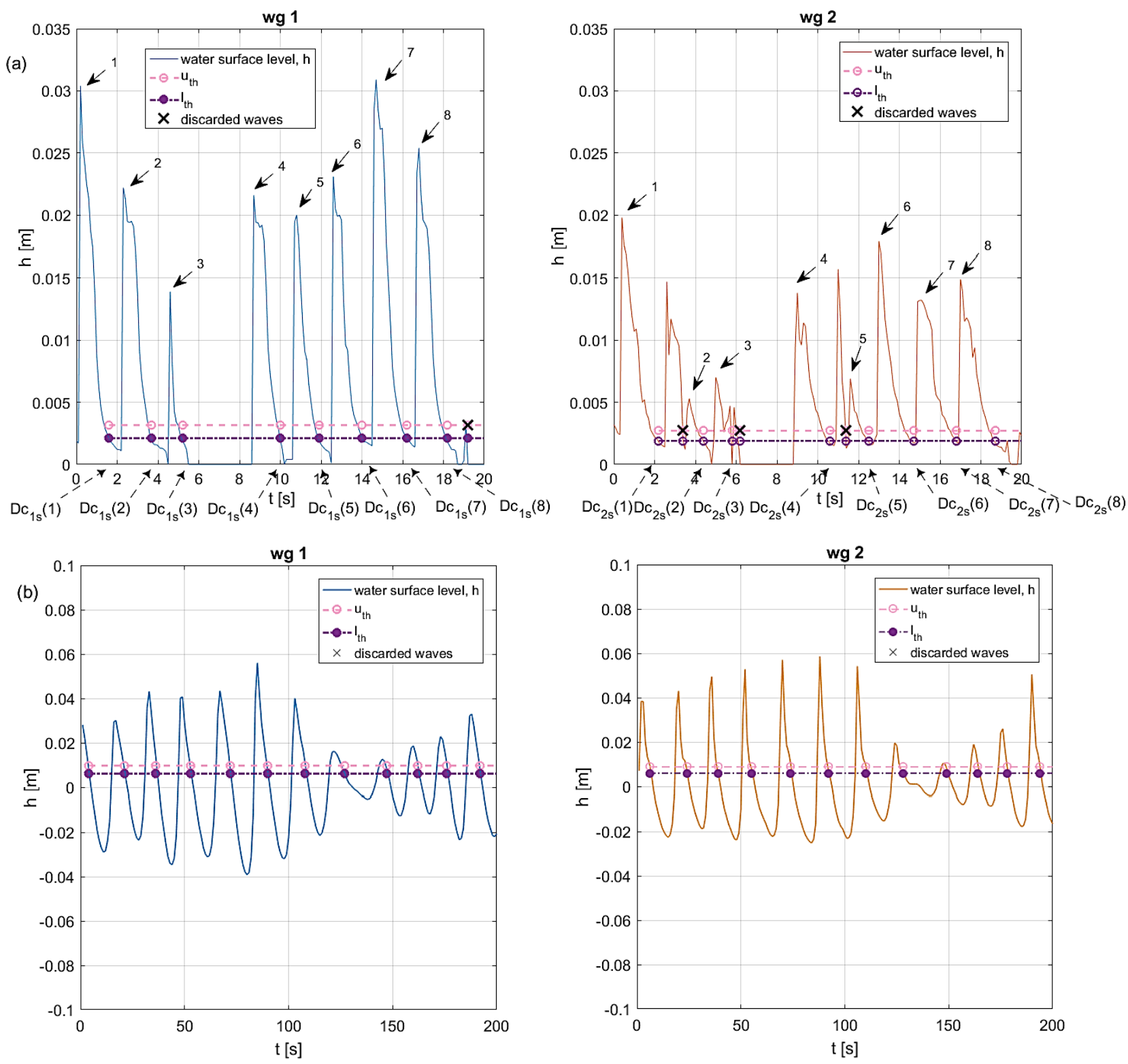

Figure $6-h$-signals measured at wg1 (left) and wg2 (right) at a dike at $R_{c} / H_{s}=1$ (panel a) and at $R_{c} / H_{s}=-0.5$ (panel b). The coupled events and the corresponding instants tdc are indicated and numbered (panel a). The discarded uncoupled events are marked with black crosses. 
To ensure a correct identification (and coupling) of the waves also in case of extremely rare overtopping, another threshold of the $h$-signals has been defined in the tdc algorithm. This parameter is an upper threshold $u_{t h}$, which is set greater than a certain percentage of $I_{t h}$ and it is used to discard the "small" oscillations of $h$-signal whose amplitude is lower than the thresholds difference $\left(u_{t h} I_{t h}\right)$.

It is not possible to univocally define the values of $I_{t h}$ and $u_{t h}$, as the definition depends on the nature (numerical, experimental) and the level of noise of the input signals and on the characteristic of the single case to be processed. Based on the analyses carried out on the available laboratory (datasets HT, HS, AAU and UB-exp) and numerical (UB-num) records, the determination of $I_{\text {th }}$ and $u_{\text {th }}$ may vary according to:

- the emergence or submergence of the structure crest, $R_{c}$. The lower the $R_{c}$, the higher the wave run-up and the lower the wave energy dissipation. Hence, for a given wave attack (same $H_{s}$ and $T_{m-1,0}$ ), the amplitude of the waves is generally lower over emerged structures $\left(R_{c}>0\right)$ than over submerged or zero-freeboard structures $\left(R_{c} \leq 0\right)$. In conclusion, the difference $\left(u_{t h}-I_{t h}\right)$ should be lower for $R_{c}>0$ than for $R_{c} \leq 0$;

- the significant wave height, $H_{s}$. The difference $\left(u_{t h}-I_{t h}\right)$ should be a function of $H_{s}$, as the amplitude of the bursts of the $h$-signals to be discarded depends on the amplitude of the incident waves;

- the distance between the wg1 and wg2, diswg, in case of 2 (or more) wgs. The greater diswg, the greater the wave energy dissipation and the reduction of the amplitude of the wave at wg2 with respect to wg1.

Though the parameters $u_{\text {th }}$ and $I_{\text {th }}$ can be customized by the user of the procedure upon necessity, it is suggested to set the values of $u_{\text {th }}$ and $I_{\text {th }}$ accounting for the following recommendations:

- in case of $R_{c} \geq 0, I_{\text {th }}$ should be set equal to the level of the structure crest (typically, 0 ) or to the minimum of the $h$-values if a small layer of water is present over the crest (see Fig. 6-a);

- in case of $R_{c}<0, I_{\text {th }}$ should be set equal to the mean of the $h$-signal or to the still water level;

- based on the number of bursts to be discarded, $u_{t h}$ can be increased of a certain percentage $p$ of $H_{s}$ with respect to $I_{t h}$, i.e. $u_{t h}=I_{t h}+H_{s} / p$;

- to account for the dissipation over the crest, the difference $\left(u_{t h}-l_{t h}\right)$ should be greater for wg1 than for wg2, especially in case of $R_{c}>0$;

- to keep all the bursts, it is possible to simply set $u_{t h}=l_{t h}$.

\subsection{Wave coupling}

A "coupled event" (or coupled wave) is an event that is firstly identified at wg1 and consecutively at wg2 after a certain time lag necessary to the wave propagation from wg1 to wg2. The coupling occurs if a series of criteria are satisfied to ensure that the events recognized at the $2 \mathrm{wgs}$ are the same event that has propagated from wg1 to wg2.

Figure 6-a compares the results of the tdc applied to the signal $h$ at $\mathrm{wg} 1$ and $\mathrm{wg} 2$ of the example numerical test of Fig. 1. In Figure 6-a, $h$ shows a non-negligible damping and a significant change of the wave shape occurred in the propagation between wg1 and wg2. Due to the modification 
of the signal, the tdc has identified a different number of events, and specifically: 9 events at wg1 and 11 waves at wg2. Figure 6-b provides for comparison the results of the tdc applied to the same dike in submerged conditions $\left(R_{d} H_{s}=0.5, H_{s}=0.1 \mathrm{~m}, T_{m-1,0}=1.8 \mathrm{~s}\right)$. In the case of Figure $6-b$, the $h$-signals at wg1 and wg2 are very similar, no significant shape irregularity appears and the same number of waves is recognized at $\mathrm{wg} 1$ and $\mathrm{wg} 2$.

The coupling step of the procedure is the algorithm that:

- $\quad$ processes the first-step-outputs, i.e. $Z \mathrm{Zcr}_{1}, \mathrm{Ztr}_{1}, \mathrm{Dc} \mathrm{c}_{1}$ at $\mathrm{wg} 1$ and $Z \mathrm{Zr}_{2}, \mathrm{Ztr}_{2}, \mathrm{Dc}_{2}$ at wg2;

- checks the satisfaction of a set of criteria to couple the corresponding waves at the $2 \mathrm{wgs}$;

- provides as final output the time-ordered sequence of the "coupled events", i.e. $Z \mathrm{Cr}_{1 \mathrm{~s}}, \mathrm{Z} \operatorname{tr}_{1 \mathrm{~s}}$, $D c_{1 s}$ and $Z \mathrm{cr}_{2 \mathrm{~s}}, Z \operatorname{tr}_{2 \mathrm{~s}}, D c_{2}$, see Figure 6-a. From now on, the subscript "s" is used to refer to the "coupled events".

While the number of the elements of the sequences of $D c_{1}$ and $D c_{2}$ may differ depending on nw1 and nw2, the lengths of $D c_{1 s}$ and $D c_{2 s}$ are equal. Each element of $D c_{1 s}$ does have a

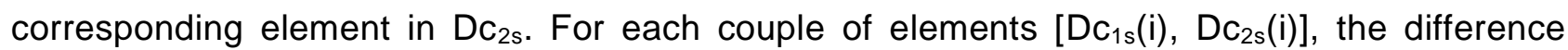
$D c_{1 s}(i)-D c_{2 s}(i)$ represents the time of propagation of the single wave from wg1 to wg2.

The coupling criteria to be satisfied are based on the definition of the minimum and maximum time lags ( $d t_{\min }$ and $d t_{\max }$ ) that may occur for the wave propagation from wg1 to wg2. These time lags depend in turn on:

- diswg, see Fig. 1-a;

- the celerity $c$ of the single waves, which depends also on the thickness of the water layer over the structure crest $h(c \alpha \sqrt{g h})$. Therefore, $c$ - and the time lags - vary also with $R_{c}$; In the coupling algorithm, $d t_{\min }$ and $d t_{\max }$ vary with the peak wave period $T_{p}$ and with the sampling frequency sf (or sampling time interval) of the sea surface signal. Their values are defined as follows:

$\left\{\begin{array}{l}d t_{\min }=\max \left(\frac{d i s w g}{c_{d w}} ; \frac{1}{s f}\right) \text {, with } c_{d w}=\frac{L_{o, p}}{T_{p}} \\ d t_{\max }=\frac{d i s w g}{c_{s w}}, \text { with } c_{s w}=\min \left(\sqrt{g h_{1}}\right)\end{array}\right.$,

where $c_{d w}$ and $c_{s w}$ represent the celerity in deep water and in shallow water, respectively.

It is assumed that $c_{d w}$ is the maximum possible wave celerity which therefore determines $d t_{\min }$. In eq. (1), the peak wave period and length, $T_{p}$ and $L_{o, p}=g \cdot T_{p}^{2} /(2 \pi)$, are the deep water values that are used as theoretical upper limit for the wave celerity. Note that $d t_{\min }$ might not correspond to $c_{d w}$ but to the minimum sampling time step $1 / s f$ because of the inherent constraint imposed by $s f$. Actually, sf does affect the accuracy of the celerity assessment. A too-low value of sf may be insufficient to catch the wave propagation from wg1 to $\mathrm{wg} 2$ and the tdc analysis may register the $i$-th wave passage at the same time, i.e. $D c_{1}(i)=D c_{2}(i)$. When this happens, the coupling procedure is forced to discard the event, resulting into a loss of data and an underestimation of the maximum and mean value of $c$. The sufficiency/insufficiency of $s f$ depends on several factors, such as: diswg, the actual celerity of the single waves, which depends in turn on the structure emergence/submergence, wave characteristics, etc. Lykke Andersen et al. (2011) suggested to 
consider a minimum distance among the gauges that equals 5 samples, i.e. $5 / s f$, assuming a maximum celerity of $2 \mathrm{~m} / \mathrm{s}$. In other words, diswg should be $\geq 2 \cdot(5 / \mathrm{sf})=10 / \mathrm{sf}$. In this work, diswg was in the range $5 / s f-12 / s f$. We can recommend that $d i s w g \geq c_{d w} / s f$, or at the contrary, that $s f \geq c_{d w} /$ diswg.

On the contrary, $c_{s w}$ is computed based on $\min \left(\sqrt{g h_{1}}\right)$, i.e. on the minimum of the values $h_{1}$ of the water surface elevation recorded at wg1 at the instants Icr $_{1}$. In other words, $h_{1}$ is the record of the values extracted from $h\left(\mathrm{wg}_{1}, t=\operatorname{Icr}_{1}(\mathrm{i}), \mathrm{i}=1, \ldots, \mathrm{nw} 1\right)$ and it is therefore assumed the minimum possible $c$ determining in turn $d t_{\max }$. Clearly, the value of $c_{s w}$ depends on the sensitivity of the wg and on the value of $\left(u_{t h}-l_{t h}\right)$ adopted to detect the minimum $h_{1}$-value.

It is important to remark that the coupling algorithm and the definition of $d t_{\min }$ and $d t_{\max }$ of Eq. (1) are valid for non-oblique waves only. For 3D waves, there might be a change in the flow direction over the structure crest, and therefore the wave celerities should be derived from a least-square fitting of the different time lags at a larger number of wgs (minimum 3, Lykke Andersen et al., 2011).

Based on $c_{s w}$ and $c_{d w}$, the coupling procedure associates 2 waves if the time lag between the 2 instants of tdc is included within [ $\left.d t_{\min } ; d t_{\max }\right]$. All the identified events that cannot be coupled are discarded.

In Figure 6-a, the coupled events are marked with the arrows and numbered progressively to highlight the correspondences between the two plots. The Figure shows that 8 events have been coupled, while 1 event from wg1 and 3 events from wg2 have been discarded (black crosses upon the circles) because:

- they actually do not have a corresponding event at the other wg (see, for example, the event around $6 \mathrm{~s}$ or the wave around $11 \mathrm{~s}$ at wg2);

- despite one event is identified at wg1, its amplitude becomes lower than $u_{t h}$ or than $\left(u_{t h}-I_{t h}\right)$ at wg2 (see the event at $19 \mathrm{~s}$ at wg1 in Figure 6);

- they are just irregularities of the shape of one larger event: this is the case of the waves with $t d c \approx 3.5 \mathrm{~s}$ and $t d c \approx 4.5 \mathrm{~s}$ at $w g 2$, which clearly belong to the same wave (nr. 2).

The result of the coupling procedure for the selected test (Figures 1 and 6-a) is qualitatively provided in Figure 7, which displays the wave signals at wg1 and wg2, once all the uncoupled events are discarded.

Once the time-ordered sequences of the coupled events $\mathrm{Dc}_{1 \mathrm{~s}}$ and $\mathrm{Dc}_{2 \mathrm{~s}}$ are derived, the timeordered sequence of the $c$-values is obtained as follows:

$c(i)=\frac{\operatorname{diswg}}{\mathrm{Dc}_{2 \mathrm{~s}}(\mathrm{i})-\mathrm{Dc}_{1 \mathrm{~s}}(\mathrm{i})}$,

where $i$ is the $i$-th element of $D c_{1 s}$ and $D c_{2 s}$ (i.e. the $i$-th coupled event).

In 5 cases of extremely rare overtopping, the coupling procedure failed because nw2 was significantly (>40-50\%) higher than nw1. This happened: i) for permeable structures, when 
contemporarily $R_{c}>0$ and $H_{s} / L_{m-1,0}>4 \%$ (2 out of 33 tests from dataset AAU), and ii) for smooth dikes when contemporarily $R_{c} / H_{s}>1$ and $H_{s} / L_{m-1,0} \geq 4 \%$ (3 out of 94 tests from dataset UB-num).

An algorithm has been implemented in the procedure to achieve the wave coupling also in these conditions by discarding more bursts at wg2 and consequently reducing nw2. Such algorithm iteratively increase of $5 \%$ the amplitude of $\left(u_{t h}-I_{t h}\right)$ by reducing $I_{t h}$ and increasing $u_{t h}$ with respect to the first guess until $|n w 1-n w 2| / n w 1$ is lower than the $30 \%$. The value of $I_{\text {th }}$ cannot of course drop below 0 . By applying this algorithm, the wave coupling was achieved for the 5 tests after one iteration only. The application of this algorithm is optional, but the user should be aware that if (nw2-nw1)/nw1>40-50\%, the wave coupling might fail. This may happen in the following cases.

- Relatively rare overtopping, i.e. $q<10^{-4} \mathrm{~m}^{3} /(\mathrm{sm})$;

- smooth structures at $R_{c} / H_{s}>1$;

- permeable structures at $R_{c} / H_{s}>0.5$ subjected to relatively steep waves, $H_{s} / L_{m-1,0}>4 \%$.

It was instead verified that in the opposite case, i.e. when nw2 $<<n w 1$, the coupling procedure does not fail, because all the waves that are detected at wg1 but not at wg2 are simply discarded. Typically, the case nw $2<<n w 1$ occurs for rubble mound structures and high rates of volume percolation along the structure crest. The robustness of the procedure has been tested up to cases of percolation rates of $60-70 \%$, which correspond to (nw2/nw 1 ) $<40 \%-50 \%$.

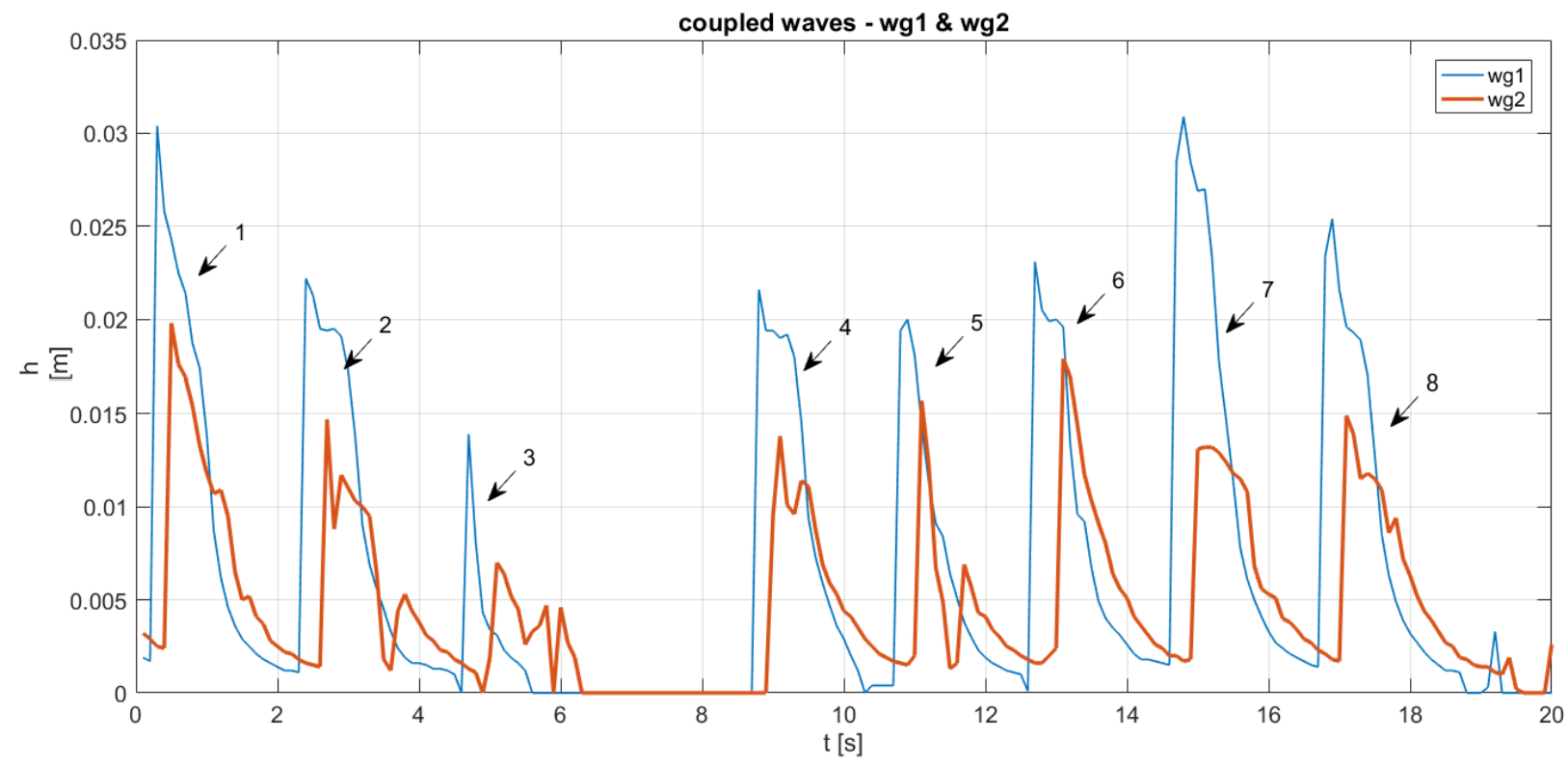

Figure 7 - Coupled $h$-signals registered at the off-shore and in-shore edges of the dike crest (wg1 and wg2, respectively). Data belonging to the same numerical test of Fig. 5.

As a final remark, the coupling algorithm can be applied to more than two wgs. In this case, the user is required to provide the $h$-signals and the diswg values for each pair of wgs to be processed and the algorithm will compute the time-ordered sequences of coupled events for each pairs of wgs. 


\subsection{Validation}

In this Sub-section the procedure is applied to the datasets HT and HS to respectively validate the identification (Sub-section 3.3.1) and the coupling (Sub-section 3.3.2) step.

\subsubsection{Identification of the overtopping volumes}

Hughes and Thornton (2016) noticed that the identification of overtopping waves by means of standard procedures may lead to inaccurate results and therefore adopted a "human supervised automatic procedure", which essentially consisted of a manual correction of the outcomes provided by their automated procedure.

Here the new semi-automatic procedure is applied to the identification of the overtopping volumes ( $V$ of the same 8 experiments (Table 3 ) on wave overtopping selected by Hughes and Thornton (2016) and elaborated with the supervised method (dataset HT).

The identification of the overtopping volumes $V$ follows essentially the methodology proposed by Hughes and Thornton (2016) and it is structured in the following steps.

- Extraction of the time series of the numerical flow discharge $(q)$ measured at the offshore edge of the structure crest. For each time step, the instantaneous value of $q$ is the result of the product of the average value (along the vertical profile) of the cross-shore directed flow velocity $(u, \mathrm{~m} / \mathrm{s})$ by the value of the corresponding flow thickness $(h, \mathrm{~m})$. In case of an offshore directed flow $(u<0)$, the value of $q$ is set to 0 . The example discharge time series used by Hughes and Thornton, 2016 is here reported in Figure 8.

- Automatic detection of the individual overtopping volumes $V$ by means of the tdc analysis of the discharge time series (Fig. 8-a). Note that the identification algorithm is here applied to process a time-discharge signal $(q)$ instead of a sea surface level signal $(h)$ as in the description of the algorithm itself (Sub-section 3.1). Therefore, in this case the values of the 2 threshold $l_{\text {th }}$ and $u_{\text {th }}$ are set as a functions of $q$ (instead of $H_{s}$ and $R_{c}$, as described in Subsection 3.1, where the procedure was applied to process a water level signal), and precisely:

o the upper threshold $u_{\text {th }}$ is set equal to the minimum between $q_{\text {mean }} / 4$ and $10^{-4} \mathrm{~m}^{3} / \mathrm{s}$ per $\mathrm{m}$, where $q_{\text {mean }}$ is the mean of the values of $q$;

o the lower threshold $l_{\text {th }}$ is set equal to $q_{\text {mean }} / 10$.

The value of $q=10^{-4} \mathrm{~m}^{3} / \mathrm{s}$ was selected by Hughes and Thornton (2016) as the minimum "arbitrarily small instantaneous discharge value of $q$ ". In other words, Hughes and Thornton (2016) "arbitrarily" decided to neglect the volumes corresponding to discharges $<10^{-4} \mathrm{~m}^{3} / \mathrm{s}$. To identify the closest number of events to the number detected by Hughes and Thornton (2016), the values $q_{\text {mean }} / 4$ and $q_{\text {mean }} / 10$ were introduced. By changing the values of $I_{\text {th }}$ and $u_{t h}$, a higher number of overtopping volumes can be detected. The procedure is able to catch any overtopping event by simply lowering $u_{t h}$ and the distance between $u_{t h}$ and $l_{t h}$, no matter how small the wave is. 
In the example of Figure 8-a, the procedure recognized 17 overtopping waves (marked by the circles representing the thresholds) and discarded the small waves around 5600 time steps because their amplitude is lower than $u_{t h}$. The automated procedure of Hughes and Thornton (2016) failed in the identification of the waves \#69, \#71 and \#72, which were recovered by a visual examination of the signal.

- Wave-by-wave integration of $q$ : for each overtopping wave recognized by the tdc procedure, the $V$-value is computed through the numerical integration of the overtopping signal. The integration is performed with the trapezoidal method, using a $0.025 \mathrm{~s}$ time-resolution, i.e. the highest possible resolution imposed by sf. Figure 8-b gives an idea of the degree of approximation of the integrating method by highlighting the areas swept by the single discharge waves corresponding to the single volumes (filled-in areas beneath the $q$ signal). The line of the cumulated volumes is shown with reference to the right scale of Figure 8-b.

506
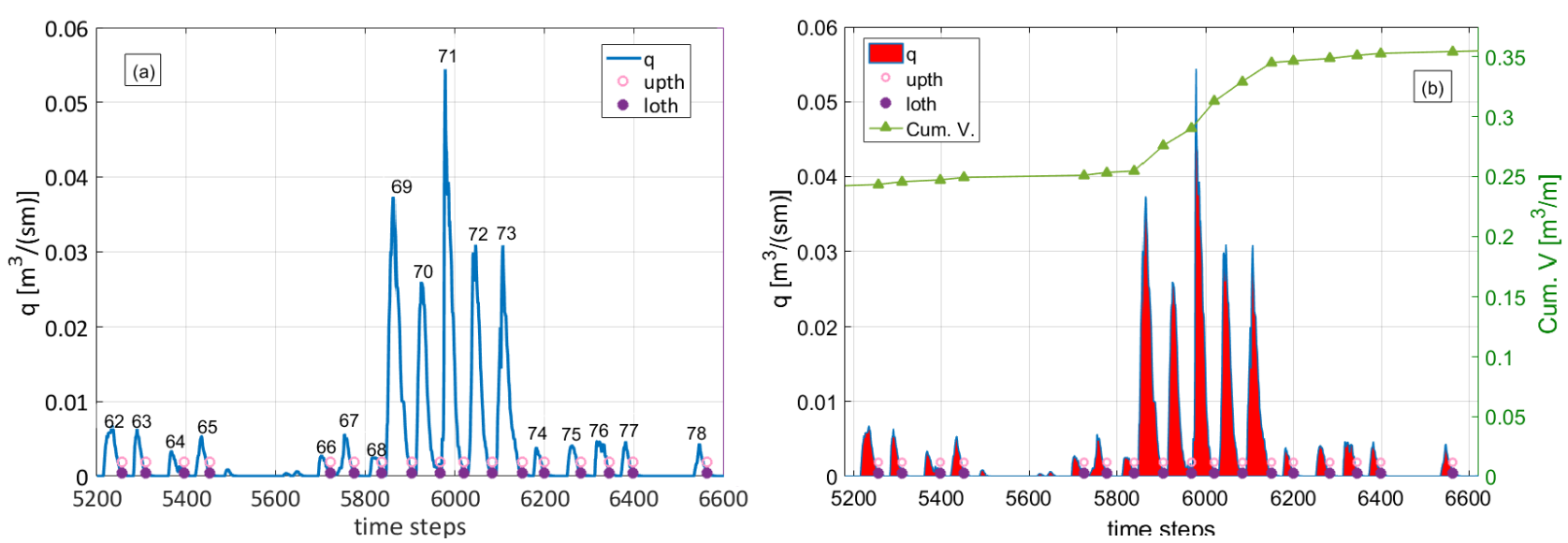

Figure 8 - Time evolution of the overtopping discharge $(q)$ measured at the offshore edge of the dike crest (a) for one of the tests from the dataset HT, and corresponding overtopping volumes (b). In panel (b), the line of the cumulated volumes is indicated with reference to the right scale. The labelling of the waves is the same used by Hughes and Thornton (2016).

513 The results of the application of the new procedure to the dataset HT are summarized in Table 5143 in comparison to the results achieved with the supervised procedure of Hughes and Thornton 515 (2016). The section of Table 3 dedicated to the results of Hughes and Thornton (2016) includes 516 the number of $\mathrm{V}$ automatically $\left(\right.$ Auto $\mathrm{V}_{\mathrm{HT}}$ ) and manually (Man $\mathrm{V}_{\mathrm{HT}}$ ) identified, their sum (Total $517 \mathrm{~V}_{\mathrm{HT}}$ ) and their ratio (Auto $\left.\mathrm{V}_{\mathrm{HT}}\right) /\left(\right.$ Total $\mathrm{V}_{\mathrm{HT}}$ ). The section dedicated to the results of the new 518 procedure includes the automatically identified $\mathrm{V}$ (Auto $\mathrm{V}$ ) and the ratio (Auto $\mathrm{V}$ )/(Total $\mathrm{V}_{\mathrm{HT}}$ ). 519 Based on the total number of overtopping volumes (Total $\mathrm{V}_{\mathrm{HT}}$ and Total $\mathrm{V}$ ) recognized by the two procedures and the total number of incident waves $(\mathrm{Nw})$, Table 3 reports also the resulting values of the probability of overtopping (Pow) for each test: Pow $=($ Auto $\mathrm{V}) / \mathrm{Nw}$, Pow $\mathrm{HT}_{\mathrm{HT}}=\left(\right.$ Total $\left.\mathrm{V}_{\mathrm{HT}}\right) / \mathrm{Nw}$. 
more cautious estimations of Pow than of Pow $\mathrm{P}_{\mathrm{HT}}$. In the worst case (test $\# 0199,78 \%$ ), the new procedure recognizes anyway 1.6 times the number of the volumes recognized by HT without the manual analysis (347 volumes instead of 211 ).

The new procedure provides a remarkably improved identification of the overtopping volumes, because it gives at least the same results of HT without requiring any manual supervision.

\subsubsection{Wave coupling}

The wave celerity $c$, or the velocity of propagation of a wave front, can be estimated by measuring the time interval occurring between the passage of a wave from one gauge to the following one. In other words, $c$ can be directly derived from the coupling of the wave signals registered at 2 consecutive wgs (see Eq. (2)).

The accuracy of the coupling step of the new procedure is here assessed by comparing estimated values of $c$ to experimental measures of flow velocity $u$ over the crest of a dike available from 3 tests by Hughes and Shaw (2011) (dataset HS, Table 4). Typically, the flow over the crest of a dike occurs in shallow water and is characterized by broken waves only. In such conditions, $u$ and $c$ should be approximately equal. More precisely, it can be assumed that the maximum $u$ value for breaking waves, $u_{\max }$, is roughly similar to celerity $c$ of the wave crest (Losada et al., 2005). For example, Schüttrumpf and Oumeraci (2005) found the average ratio between $c$ and $u_{\max }$ equal to 0.97 with a standard deviation $\sigma_{\%}$ of $29.9 \%$. Since the wave breaking generally occurs when the water depth is approximately equal to the wave height, it can be concluded that in the case of the 3 tests from the dataset HS, the flow over the crest occurs in broken conditions, being the values of $H_{s} /\left|R_{c}\right|$ range from 2.33 to 8.25 (see Table 4). In such conditions, the approximation $u \approx c$ should be good and therefore the proposed validation for the coupling step meaningful. More details about this topic are discussed in Sub-section 3.4.

The new procedure has been applied to the water level signals registered at the 2 wgs (ADVs) placed over the crest of the structure. Based on the resulting time lags occurring between the couples of overtopping waves $\left(D_{2 s}-D c_{1 s}\right)$, the outcomes of the procedure have been used to derive the wave celerities $(c)$ of the single waves. The time averaged values of $c\left(c_{\text {mean }}\right)$ derived for each tests are compared in Table 4 to the corresponding upper $2 \%$ values $u_{2 \%}$ computed from the time series of $u$ measured by the ADV. For all the tests, $c_{\text {mean }}$ is always slightly lower than $u_{2 \%}$. This can be explained considering that $u_{2 \%}<u_{\max }$ is used as estimator of the maximum flow velocity. Anyway, the agreement between $u_{2 \%}$ and $c_{\text {mean }}$ is remarkable, being the ratio $c_{\text {mean }} / u_{2 \%}$ included between 1.01 (test R109) and 1.14 (test R18).

Figure 9 gives a qualitative idea of the accuracy of the procedure showing the identified and coupled waves during the first few seconds of the water level signals registered at the $2 \mathrm{wgs}$ for the test R14. Note that the wave identified at wg1 around $31 \mathrm{~s}$ has been correctly discarded as it is just a noise in the wave signal. The procedure has correctly coupled most of the overtopping waves for each test providing meaningful estimates of the celerities. 2 special cases can be 
observed in this plot: the wave between 26 and 28 seconds and the wave at $32 \mathrm{~s}$. In both cases we observe a single double-peaked wave, however in the first case the 2 peaks are recognized as two waves, while in the second case the first peak is disregarded because of the threshold values.

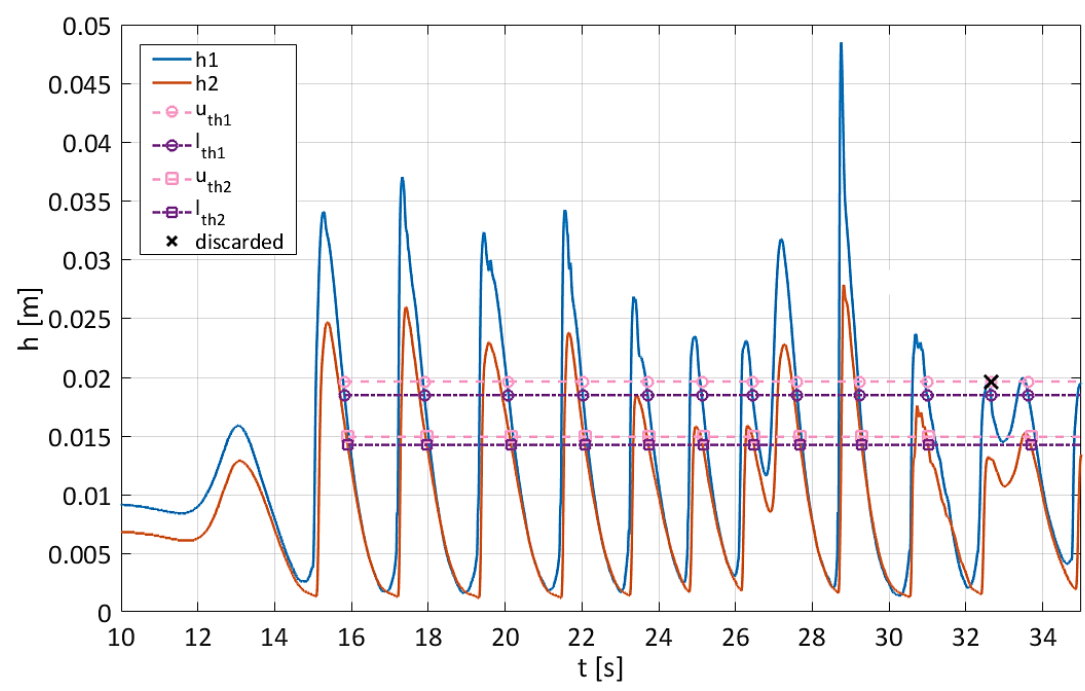

Figure 9 - Identification and coupling of the overtopping waves performed by the new procedure for one of the lab tests on levees belonging to the dataset HS (test R14). $R_{d} H_{s}=-0.155$.

\subsection{Assessment of the validity of the assumptions}

This Sub-section provides a detailed analysis of the wave celerities as outputs of the coupling step of the procedure, with the specific aims of i) further investigating and demonstrating the validity of the assumption that $u \approx c$ for broken or breaking flow conditions (Sub-section 3.4.1); ii) assess the reliability of the coupling step also in case of non-broken flow conditions (Sub-section 3.4.2).

\subsubsection{Breaking and broken flow over the crest}

The validity of the assumption that for breaking or broken waves $u \approx c$ is checked here by applying the whole procedure to the UB-exp dataset (Table 5). Since all the tests belonging to UB-exp were conducted at $R_{c} \geq 0$, the flow thickness over the dike crest is due to the water that exceeds the crest level, i.e. at each instant $h \leq\left(H-R_{c}\right)$, where $H$ is the height of the generic incoming wave. Therefore, the flow over the dike crest certainly occurs in breaking or broken wave conditions (Losada et al., 2005).

To calculate the celerities, the following methodology was adopted. The 2 steps of the procedure have been consequently applied to the time signals $h_{1}$ and $h_{2}$ derived from the UVP measurements at D4 and D6, approximately situated at the off-shore and in- shore edges of the dike crests during the UB-exp experiments (see Fig. 2 and Tab. 5). The positions D4 and D6 
represent therefore $\mathrm{wg} 1$ and $\mathrm{wg} 2$ for the UB-exp and will be referred in this way hereinafter. An example of the $h_{1}$ and $h_{2}$ signals for one of the tests $\left(R_{d} / H_{s}=1, H_{s}=0.05 \mathrm{~m}, s_{m-1,0}=3 \%, \cot \left(\alpha_{o f f}\right)=4\right.$, $G_{c}=0.30 \mathrm{~m}$ ) is shown in Figure 10. Each couple of waves identified and coupled is numbered in the Figure, while the waves discarded from the wave coupling are marked with black crosses.

591

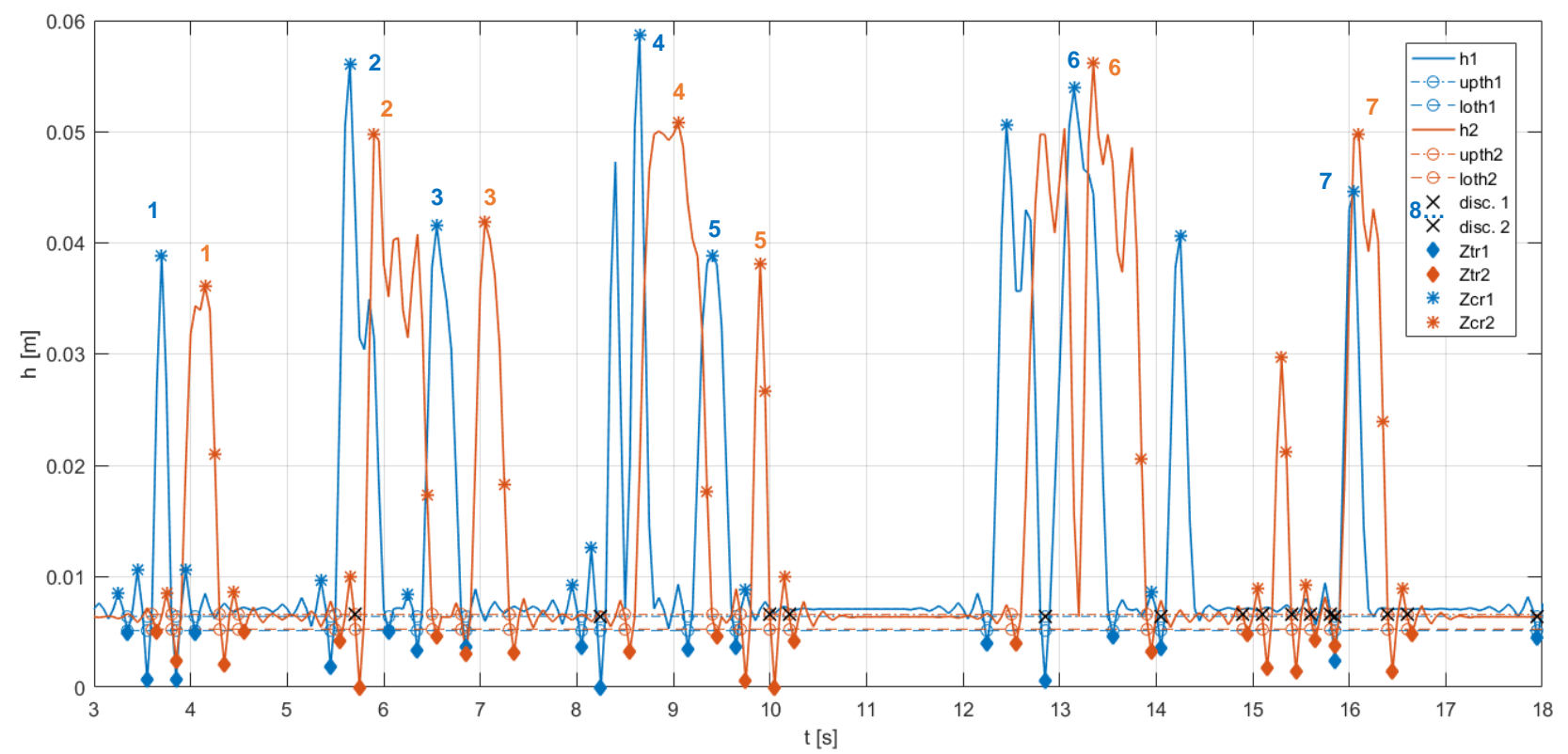

Figure 10 - Identification and coupling of the overtopping waves performed by the new procedure for one of the test from the dataset UB-exp.

For each test, the outputs of the wave coupling has been further processed to derive the time series of $c$ based on Eq. (2). Finally, the time-average values of $c, c_{\text {mean }}$, have been calculated.

As for the flow velocities, the vertical profiles of $u$ measured with the UVPs at $w g 1$ have been elaborated as follows. Firstly, for each instant, the depth-averaged values of $u$ have been derived from the vertical profiles. The resulting time series of the average $u$-values have been sorted and the upper $u_{2 \%}$ velocity values - i.e. the values of $u$ exceeded by the $2 \%$ of the incoming waves - have been derived. The maximum velocities, $u_{\max }$, have been also calculated to be compared to $C_{\text {mean }}$, according to Losada et al. (2005) and Schüttrumpf and Oumeraci (2005).

604 To qualitatively characterize the accuracy of the data collected with the UVPs, the $u_{2 \%, w g}$ values are displayed in Figure 11 as a function of the quantity $\left(g\left(R u_{2 \%}-R_{c}\right)\right)^{0.5}$, where $R u_{2 \%}$ is the wave run-up exceeded by the upper $2 \%$ of the incoming waves and is computed following EurOtop (2018). The quantity $\left(g\left(R u_{2 \%}-R_{c}\right)\right)^{0.5}$ is used in the formulae by Schüttrumpf $(2001)$, Van Gent 608 (2002) and Bosman et al. (2008) to estimate $u_{2 \%}$ at the dike off-shore edge according to the 609 following expression:

$u_{2 \%}=c_{u} \cdot\left[g\left(R_{u, 2 \%}-R_{C}\right)\right]^{0.5}, \quad R_{C} \geq 0$, 
where $c_{u}=1.37$ for Schüttrumpf (2001), $c_{u}=1.33$ for Van Gent (2002) and $c_{u}=0.30 / \sin \left(\alpha_{\text {off }}\right)$ for Bosman et al. (2008). In the formulation by Bosman et al. (2008), the coefficient $c_{u}$ is made varying with $\alpha_{\text {off }}$ to account for the effects of the structure slope, and therefore it is supposed to update the other formulations by Van Gent (2002). It is worthy to remember that Bosman et al. (2008) fitted the formulation of $c_{u}$ on values of $\cot \left(\alpha_{o f f}\right)=4$ and 6 , only. By comparing the $u_{2 \%, w g}$ values to the curves representing the literature formulae in Figure 11, it can be appreciated how all the data generally follow the same trend with $\left(g\left(R u_{2 \%}-R_{c}\right)\right)^{0.5}$ indicated by the formulae. The data at $\cot \left(\alpha_{o f f}\right)=2$ (diamonds) seems to be well fitted by the curve by Bosman et al. (2008) extrapolated for $\cot \left(\alpha_{\text {off }}\right)=2$. The data at $\cot \left(\alpha_{\text {off }}\right)=4$ (circles) are on average slightly higher than the data at $\cot \left(\alpha_{\text {off }}\right)=4$, though no particular effect of the slope angle is evident. The expressions by Bosman et al. (2008) for $\cot \left(\alpha_{o f f}\right)=4$, by Schüttrumpf (2001) and by Van Gent (2002) represent upper envelopes to the data.

623

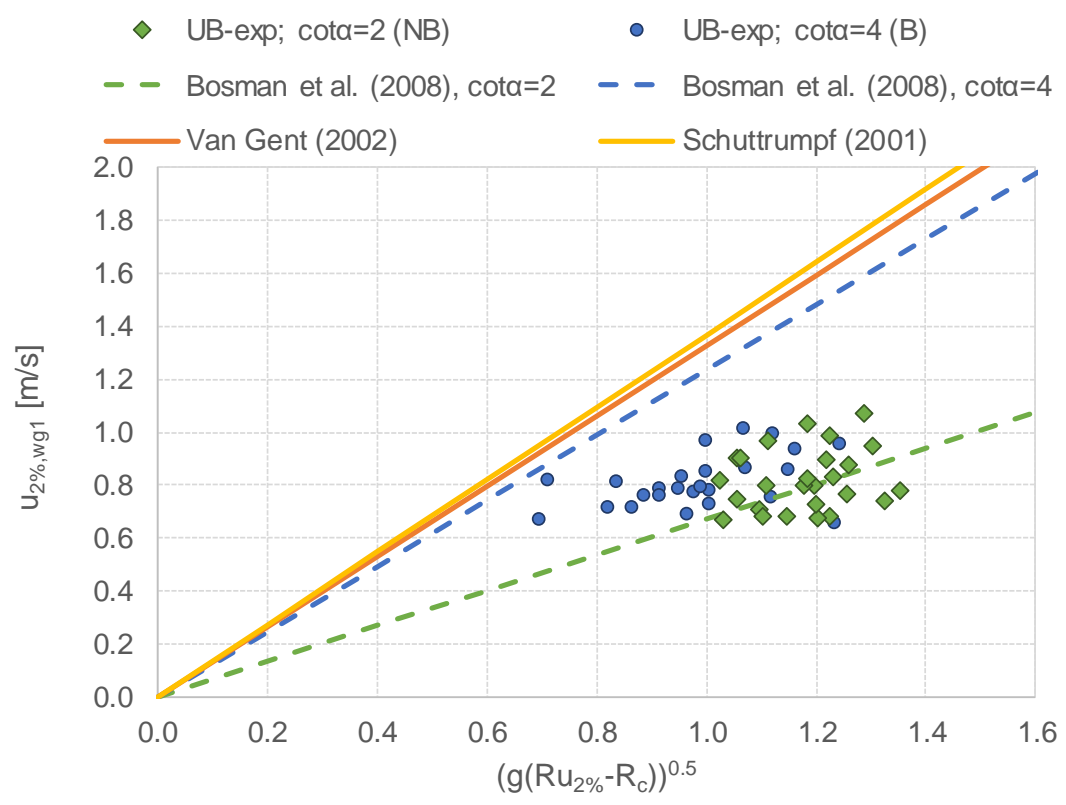

Figure 11 - Comparison among the upper $2 \%$ values of $u$ measured at $w g 1\left(u_{2 \%, w g 1}\right)$ and the literature formulae as a function of the wave run-up $\left(g\left(R u_{2 \%}-R_{c}\right)\right)^{0.5}$. Data from UB-exp.

As long as the approximation $u_{\text {max }} \approx C_{\text {mean }}$ holds, it is expected that the $c_{\text {mean }}$ values are in good agreement with the $u_{\max , w g 1}$ values. The comparison among $u_{\max , w g}$ and $c_{\text {mean }}$ is proposed in Figure 12. The chart includes the bisector (continuous) line representing the optimal condition $u_{\text {max } w g} 1=c_{\text {mean }}$ and the range of $\pm 29.9 \%$ around it (dashed lines), where $29.9 \%$ is the standard deviation between $u$ and $c$ found by Schüttrumpf and Oumeraci (2005). In the Figure, all the data are straightly included within the $\pm 29.9 \%$ bands, denoting a higher level of agreement between celerities and velocities. Specifically, it is found that on average $c_{\text {mean }} / u_{\text {max,wg } 1}=0.95$ with a standard deviation $\sigma_{\%}=7.4 \%$. These findings support and prove the validity of the assumptions made to verify the accuracy of the coupling step for flow in broken or breaking wave conditions (Sub-section 3.3.2). 


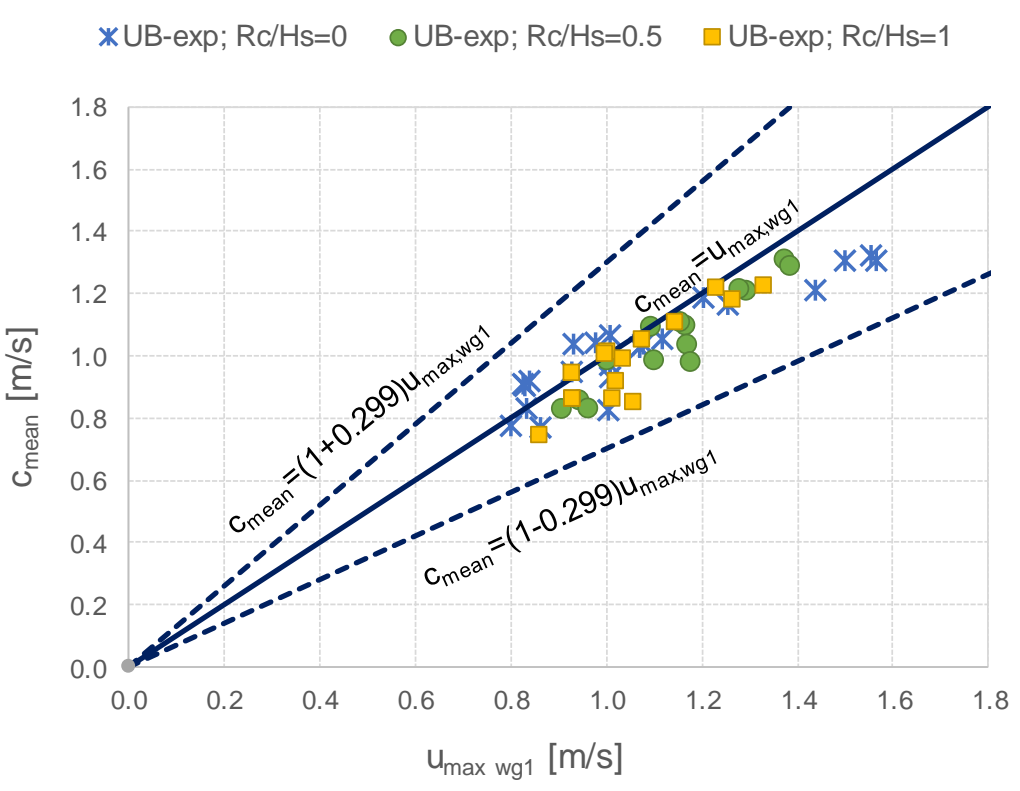

Figure 12 - Comparison among mean wave celerities $\left(c_{\text {mean }}\right)$ estimated with the new procedure applied at wg1 and wg2 and the max values of $u$ measured at wg1 $\left(u_{m a x, w g}\right)$. Data from UB-exp.

\subsubsection{Non-breaking flow over the crest}

In case of structures at negative crest freeboard, the assumption that the flow is characterized by broken waves only holds no more. The overtopping process includes a storm surge overflow component. In such conditions, the approximation $c \approx u$ is no more realistic and cannot be used to verify the consistency of the celerity values computed by the new procedure. With the exception of human visualization of the coupled waves, no reference method is available for a rigorous verification of the coupling step of the procedure in case of $R_{c} \leq 0$.

An indication about the reliability of the coupling step of the new procedure at any crest level, and specifically in case of $R_{c} \leq 0$, can be obtained by cross-correlating the $2 h$-signals at the 2 consecutive wgs. The average time lags between the $2 h$-signals resulting from the crosscorrelation, lag $\left(x_{\text {corr }}\right)$, can be compared to the mean values of the array $\left(\mathrm{Dc}_{1 \mathrm{~s}}-\mathrm{Dc}_{2 \mathrm{~s}}\right)$ calculated with the new procedure. The mean wave celerities $c\left(x_{c o r r}\right)=l a g\left(x_{c o r r}\right) / d i s w g$ and $c_{\text {mean }}=\operatorname{mean}\left(\mathrm{Dc}_{1 \mathrm{~s}^{-}}\right.$ $\mathrm{Dc}_{2 \mathrm{~s}} /$ /diswg can be also compared. It is expected that the statistical distribution of the $c$-values is more uniform for submerged than for zero-freeboard structures for the presence of the constant over-flow component over the structure crest. Therefore, the average $c\left(X_{\text {corr }}\right)$ resulting from the cross-correlation are expected to be more representative of the actual distribution of the $c$-values, i.e. that $c\left(x_{\text {corr }}\right) \approx c_{\text {mean }}$ when $R_{c}<0$.

659 The cross-correlation function has been applied to the available data at $R_{d} / H_{s} \leq 0$ from the dataset UB-num. In this case, wg1 and wg2 are the numerical gauges placed in proximity of the offshore and in-shore edges of the dike crest (see Fig. 1), respectively providing the time signals $h_{1}$ and $h_{2}$. The same methodology described in Sub-section 3.4.1 has been followed to derive the $c_{\text {mean }}$ values from the outcomes of the procedure. The comparison among the values of 
$c\left(x_{c o r r}\right)$ and $c_{\text {mean }}$ is qualitatively provided in Figure 13 , by grouping the data at $R_{c}=0$ and $R_{c}<0$. This Figure suggests that the results of the procedure and of the cross-correlation are very similar and the scatter is limited $\left(\mathrm{R}^{2}=0.96\right.$ for both the groups of data). The data at $R_{c}=0$ are more symmetrically distributed around the bisector line $\left(c_{\text {mean }} / c\left(x_{c o r r}\right)=1.00\right.$, with $\left.\sigma_{\%}=11 \%\right)$, while the values of $c_{\text {mean }}$ tend to be slightly lower than $c\left(x_{c o r r}\right)$ when $R_{c}<0$ ( $c_{\text {mean }} / c\left(x_{c o r r}\right)=0.88$, with $\left.\sigma_{\%}=5 \%\right)$. Actually, the greater the water layer over the structure crest $h$, the higher the $c$-values. In case of $R_{c}<0$, it is likely that the real $c$ values exceed the upper limit of $c(\approx 2.7 \mathrm{~m} / \mathrm{s})$ that can be estimated with the new procedure due to $s f=20 \mathrm{~Hz}$. In conclusion, this analysis confirms that the results of the procedure are meaningful and physically coherent, and the main limit is represented by sf.

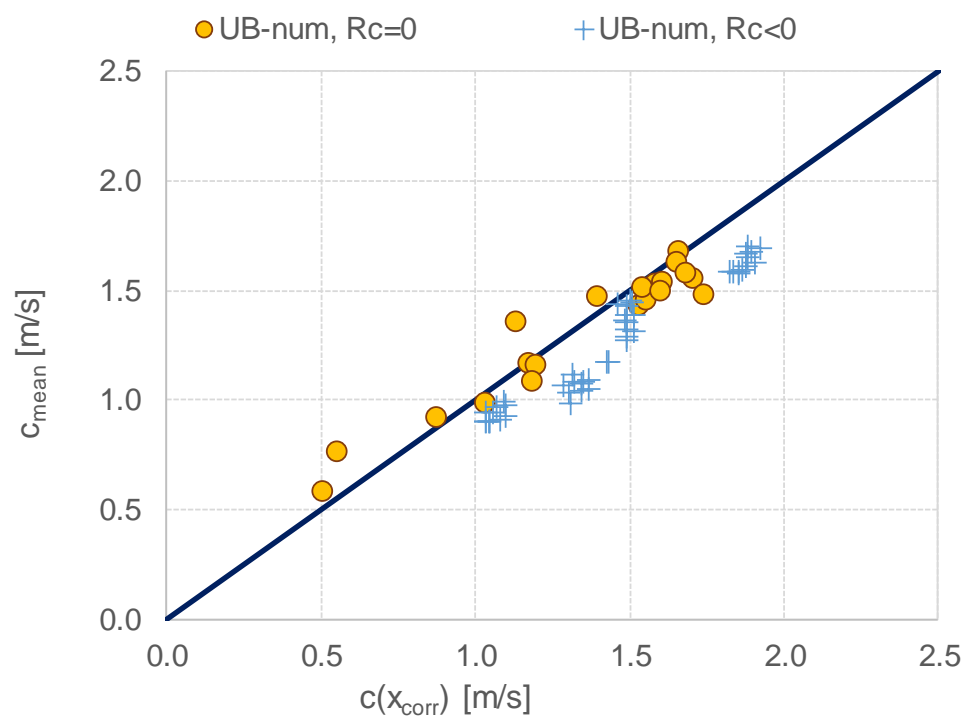

Figure 13 -Values of the wave celerities $\left(c\left(x_{\text {corr }}\right)\right)$ derived from cross-correlation of the $2 h$-signals at wg1 and wg2 compared to the mean wave celerities ( $\left.c_{\text {mean }}\right)$ estimated with the new procedure. Data from UB-num at $R_{c} / H_{s} \leq 0$.

\section{Wave overtopping at smooth dikes}

In this Section the principal results and applications of the procedure are presented: i) the estimation of the probability of overtopping (Sub-section 4.1); ii) the calculation of the average overtopping discharge (Sub-section 4.2); iii) the identification of the extreme overtopping volumes (Sub-section 4.3). 


\subsection{Probability of overtopping}

687

688

689

690

691

692

693

694

695

696

697

698

699

700

701

702

703

704

705

One direct application of the procedure is the calculation of the probability of overtopping of a structure $\mathrm{P}_{\mathrm{ow}}$, which can be easily determined by dividing the number of the overtopping waves (or volumes) identified by the first step to the total number of incident waves (see Sub-section 3.3.1). According to Van der Meer and Janssen (1994), $P_{\text {ow }}$ at dikes can be estimated from the following expression:

$\mathrm{P}_{\mathrm{ow}}=\exp \left(-\left(\frac{1}{x} \cdot \frac{R_{c}}{H_{m 0}}\right)^{2}\right)$, with $X \approx 0.51 \cdot \frac{R_{u, 2 \%}}{H_{m 0}}$ and $R_{c}>0$

Figure 14 shows the distribution of the values of $\mathrm{P}_{\text {ow }}$ obtained from the application of the new procedure to the tests at $R_{c} \geq 0$ of the datasets UB-exp and UB-num in comparison to the curve representing Eq. (4). For both UB-exp and UB-num, the $P_{\text {ow }}$ values are calculated based on the results of the identification step of the procedure applied at wg1 (see Figures 1 and 2). In Figure 14 , the data are plotted as function of the quantity $\frac{1}{x} \frac{R_{c}}{H_{m 0}}$ and are grouped by dataset. The Figure indicates that all the data follow the trend of the formula with $\frac{1}{x} \frac{R_{c}}{H_{m 0}}$ and most of them are included in a range of $\pm 15 \%$ (dashed lines) around Eq. (4) (continuous line). The 7 outliers fall anyway within $+20 \%$ and are all positioned over the curve. This slight bias suggests that the procedure tends to give cautious estimations of $\mathrm{P}_{\mathrm{ow}}$ for $\frac{1}{x} \frac{R_{c}}{H_{m 0}}>0.6$. In a few cases at zero or modest freeboard, there is a small overestimation of $P_{o w}=1$ : this happens when the procedure does not discard all the bursts in the wave signal generated by the wave breaking and identifies a number of waves slightly larger (less than $10 \%$ ) than the number of the incident waves.

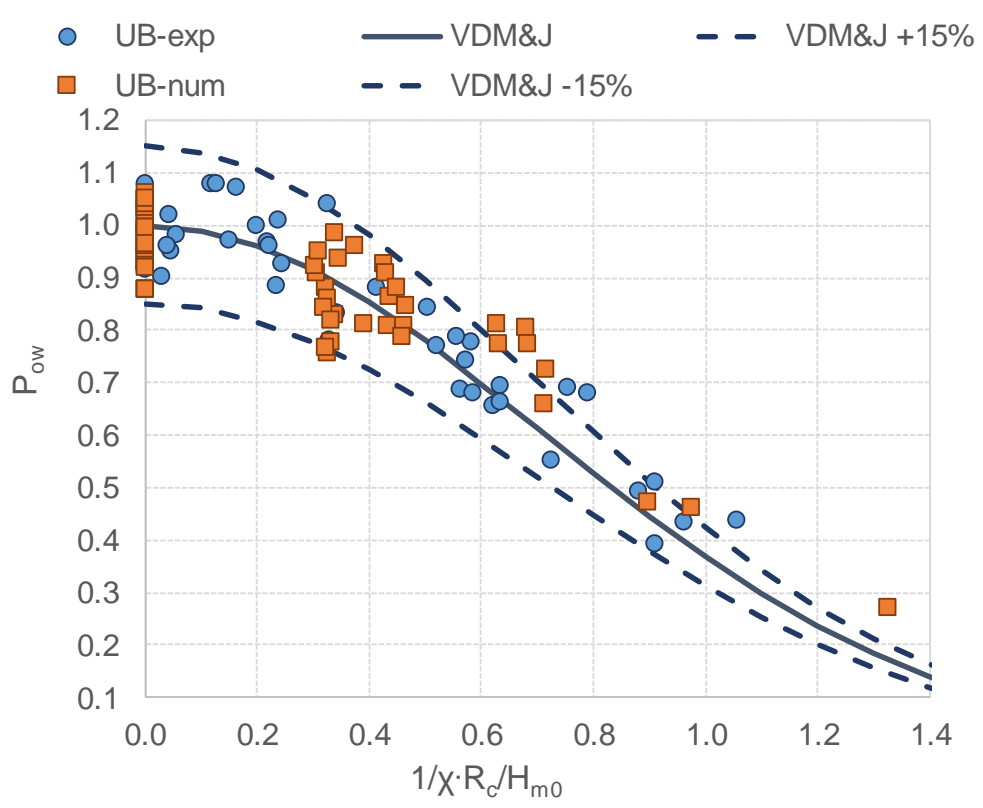

Figure 14 - Probability of overtopping $\left(P_{\text {ow }}\right)$ calculated by applying the identification step of the procedure to the datasets UB-exp and UB-num compared with the predictions by the formula by Van der Meer and Janssen, 1994 (VDMandJ, continuous line). The range of $\pm 15 \%$ around the formula is shown (VDMandJ $\pm 15 \%$, dotted lines). Data at $R_{d} H_{s} \geq 0$. 


\subsection{Overtopping discharges}

712 The wave celerities $c$ can be also integrated with the water levels $h$ and used to estimate the 713 instantaneous and average wave overtopping discharge $q$. As further application of the 714 procedure, this Sub-section presents the average values of $q$ derived from the $c$ values of the 715 datasets UB-num and UB-exp, $q_{c e l}$. Since the assumption that $c \approx u$ holds only for flow in breaking 716 wave conditions (see Sub-section 3.4), the extraction of $q_{c e l}$ from $c_{\text {mean }}$ was done for the tests at $717 R_{c} / H_{s} \geq 0$ only. Starting from the time series of $c$ and $h_{1}$ (water level signal at wg 1 at the dike off718 shore edge), the time series of $q$ were firstly obtained by multiplying the instantaneous values of $719 c$ by $h_{1}$. Then, the $q_{c e l}$ values were calculated for each test as the time-averages of the time series 720 of $q$.

721 In Figure 15, the values of $q_{c e l}$ derived for UB-num and UB-exp (panels a and b, respectively) 722 are directly compared to the average values of $q$ available from the numerical and experimental 723 724 measurements, named $q_{\text {meas. }}$. In case of UB-num, the data of $q_{\text {meas }}$ correspond to the timeaveraged values of $q$ derived from the integration of the numerical flow velocities with the flow depths, while in case of UB-exp $q_{\text {meas }}$ are the average $q$ values measured from the overtopping tank. In both the charts of Figure 15, the data are grouped by breaking (B) and non-breaking (NB) wave conditions. Such distinction follows EurOtop (2018) and it is based on the values of the Iribarren-Battjes breaker parameter $\xi_{m-10}=\tan \left(\alpha_{o f f}\right) /\left(s_{m-1,0}\right)^{0.5} \leq 2$ (B) or $>2(\mathrm{NB})$. It is worthy to stress that the distinction between $B$ and NB based $\xi_{m-10}$ refers to the occurrence of the wave breaking along the dike off-shore slope, i.e. before the dike crest. The overarching superposition for the analysis of $q_{c e l}$ is that the flow is already broken over the dike crest independently of $\xi_{m-1,0}$.

In Figure 16-a,b, the $q_{c e l}$ values are made dimensionless through $\left(\mathrm{gH}_{\mathrm{mo}}\right)^{0.5}$ and compared to the EurOtop (2018) equations 5.10 and 5.11 for the prediction of the average $q$ at dikes under $B$ and NB waves, respectively. The values of $H_{m o}$ have been calculated from the spectral analysis of the incident wave signals both in the numerical and in the laboratory channel. In these charts, the data are grouped by dataset (UB-num and UB-exp) and are displayed as functions of the 739 relative crest freeboard. The curves representing the formulae are shown as continuous lines while the interval of $\pm 5 \%$ around the curves themselves is represented through dashed lines, following EurOtop (2018). 

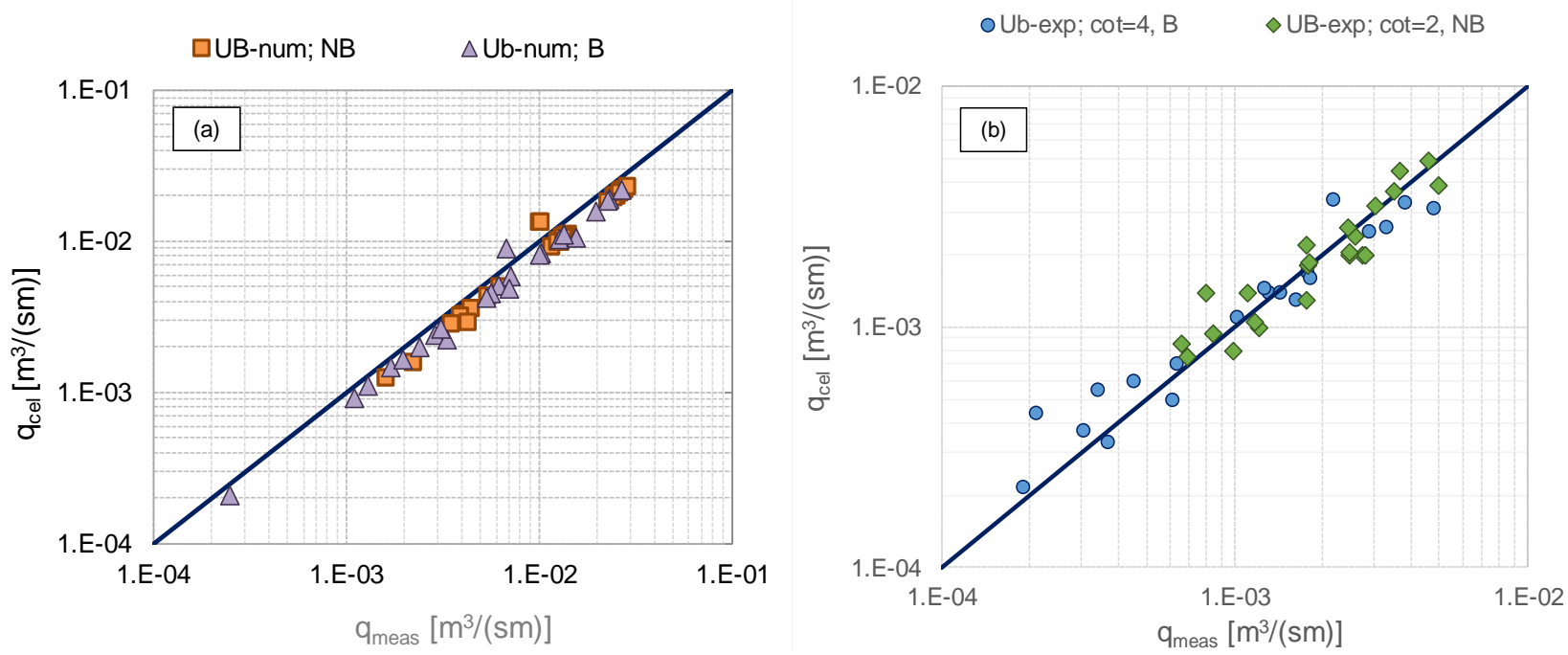

Figure 15 - Comparison among values of $q\left(q_{\text {meas }}\right)$ measured from the overtopping tank (UBexp) or derived by the integration of the numerical flow velocities with the flow depths (UB-num) and corresponding values $\left(q_{c e l}\right)$ calculated from the wave celerities obtained with the new procedure. Data at $R_{d} / H_{s} \geq 0$ grouped by breaking ("B") and non-breaking wave conditions ("NB").
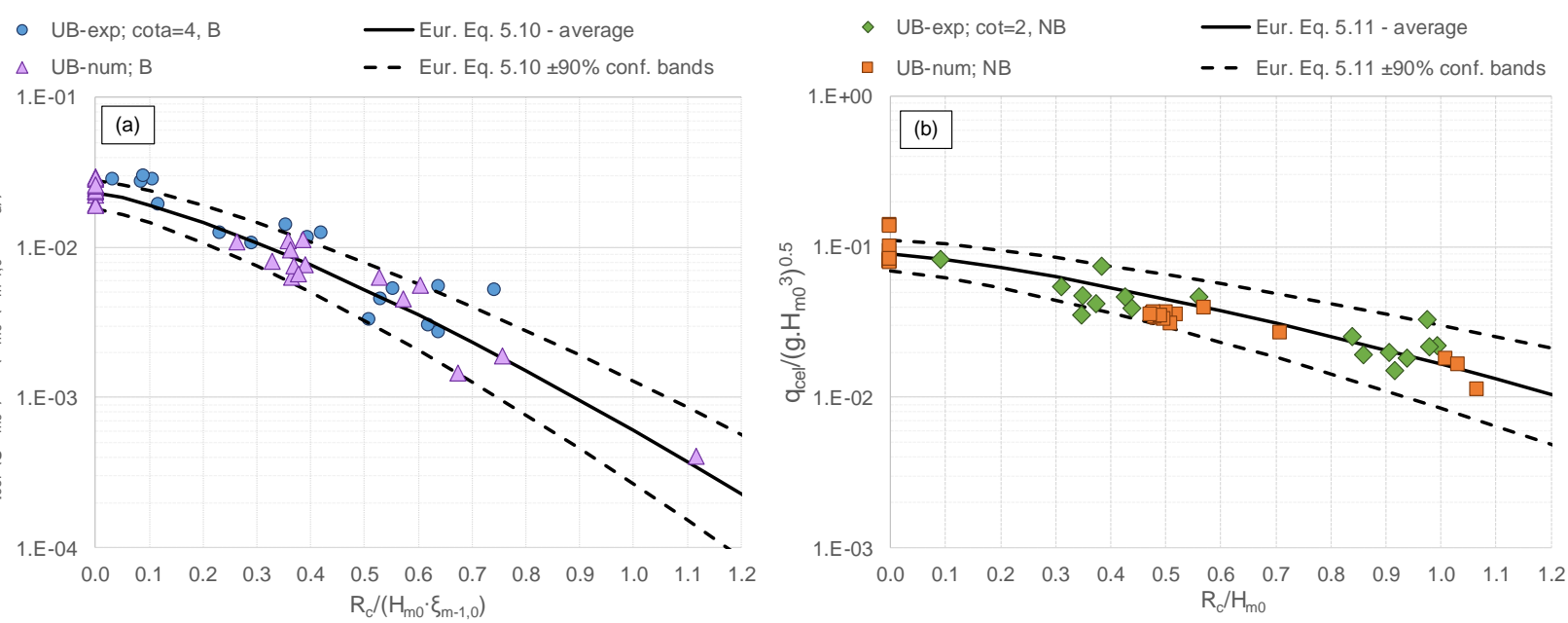

Figure 16 - Dimensionless values of $q$ calculated from the wave celerities $\left(q_{c e l}\right)$ obtained with the new procedure compared to the curves (continuous lines) representing the EurOtop (2018) formulae for the prediction of $q$. Data at $R_{d} / H_{s} \geq 0$ grouped by breaking ("B") and non-breaking wave conditions ("NB"). Datasets UB-exp and UB-num in panel a and b, respectively.

Figure 15 gives a qualitative idea of the level of agreement between $q_{c e l}$ and $q_{\text {meas }}$, while Figure 16 is meant to illustrate the trend of the $q_{c e l}$ values with the physical parameters and the predicting formulae. The quantitative indexes assessing the agreement between $q_{c e l}$ and $q_{\text {meas }}$ and between $q_{c e l}$ and the predictions of $q$ obtained with the EurOtop (2018) equations ( $q_{\text {Eur }}$ ) are collected in Table 7. For each dataset and each group of data (B and NB), Table 7 provides the values of the average ratios $q_{c e l} / q_{\text {meas }}$ and $q_{c e l} / q_{\text {Eur }}$, the corresponding standard deviations $\sigma_{\%}$ and the coefficients of determinations $\mathrm{R}^{2}$. Overall, the agreement of the $q_{c e l}$ values with $q_{\text {meas }}$ is 
remarkable, considering that $\mathrm{R}^{2}$ ranges between 0.92 and 0.98 and that $q_{\text {cel }} / q_{\text {meas }}=0.80-1.09$. Both Figure 15-a and Table 7 indicate that $q_{c e l}$ tend to slightly but systematically underestimate the $q_{\text {meas }}$ values of UB-num ( $q_{\text {cel }} / q_{\text {meas }}=0.80$ and 0.81 for B and NB waves, respectively). The cause of this underestimation is again the upper limit of $c$ at $\approx 2.7 \mathrm{~m} / \mathrm{s}$ imposed by the combination of $s f$ and diswg. However, the scatter between $q_{c e l}$ and $q_{\text {meas }}$ associated to UB-num is extremely limited $\left(R^{2}=0.97-0.98, \sigma_{\%}=9.9 \%-11 \%\right)$ and the agreement with the trend suggested by the EurOtop formulae (Fig. 16-a,b) is good, especially in case of B waves (Fig. 15-a, $R^{2}=0.96$ ). As for UB-exp, Fig. 15-b shows that most of the data are symmetrically distributed in proximity of the bisector line. The slightly higher standard deviations ( $\left.\sigma_{\%}=32 \%-34 \%\right)$ with respect to UB-num can be explained with the greater noise associated to the experimental signals (compare Fig. 10 to Fig. 7) and to the higher level of uncertainty associated to the lab measurements (see Subsection 2.4).

Table 7. Comparison between $q_{c e l}$ and $q_{\text {meas }}$ and between $q_{c e l}$ and the predictions by the EurOtop (2018) formulae $\left(q_{E u r}\right)$. Datasets UB-exp and UB-num.

\begin{tabular}{|c|c|c|c|c|c|c|}
\hline Dataset & \multicolumn{3}{|c|}{$q_{\text {cel }}$ Vs $q_{\text {meas }}$} & \multicolumn{3}{|c|}{$q_{\text {cel }}$ vs EurOtop (2018) } \\
\hline & mean $\left(q_{\text {cel }} / q_{\text {meas }}\right)$ & $\sigma_{\%}\left(\mathrm{q}_{\text {cel }} / \mathrm{q}_{\text {meas }}\right)$ & $\mathrm{R}^{2}\left(\mathrm{q}_{\text {cel }}, \mathrm{q}_{\text {meas }}\right)$ & mean $\left(q_{\text {cel }} / q_{\text {Eur }}\right)$ & $\sigma_{\%}\left(\mathrm{q}_{\text {cel }} / \mathrm{q}_{\text {Eur }}\right)$ & $R^{2}\left(q_{c e l}, q_{E u r}\right)$ \\
\hline UB-num, B & 0.80 & $11 \%$ & 0.98 & 0.98 & $8.5 \%$ & 0.96 \\
\hline UB-num, NB & 0.81 & $9.9 \%$ & 0.97 & 0.92 & $32 \%$ & 0.86 \\
\hline UB-exp, B & 1.09 & $34 \%$ & 0.92 & 1.09 & $35 \%$ & 0.89 \\
\hline UB-exp, NB & 1.06 & $32 \%$ & 0.94 & 1.01 & $24 \%$ & 0.95 \\
\hline
\end{tabular}

\subsection{Overtopping volumes}

The wave overtopping volumes $V$ are commonly treated as stochastic variables and associated with a probability distribution. According to the literature (EurOtop, 2018), the probability distribution of the exceedance of $V$ can be approximated by the Weibull distribution:

$\mathrm{P}\left(V_{i} \geq \bar{V}\right)=\exp \left(-\left(\frac{V}{a}\right)^{b}\right)$

where $P\left(V_{i} \geq \bar{V}\right)$ (or simply $P$, hereinafter) is the probability that the $i$-th individual volume $V_{i}$ is greater than a specified volume $\bar{V}$. The parameters $a$ and $b$ are the Weibull's scale and shape factors, respectively. a generally corresponds to the mean of the distribution of the V-values (Van der Meer and Janssen, 1994), while $b$ is the slope of the straight line fitting the Weibull's distribution of the "extreme" $V$-values in a double-log chart $\ln (V / a)$ vs $\ln (-\ln (P))$. Several methods are proposed in the literature to identify the "extreme" $V$-values (upper $50 \%$, upper $20 \%$, upper $10 \%$, human selection of the upper tail on the distribution), see for instance Pan et al. (2016) and Molines et al. (2019). In this work, the automatic selection of the upper $20 \% \mathrm{~V}$-values was preferred as best compromise, see the analysis performed by Formentin and Zanuttigh (2018, 
b). However, the choice of the percentage of the data to be used seems not to significantly affect the estimation of the maximum $V$-values as already demonstrated by Pan et al. (2016).

The methodology described in Sub-section 3.3.1 for the dataset HT has been also applied to the datasets UB-num and UB-exp to derive the individual overtopping volumes and the relative exceedance probability distribution $P$. Therefore, the values of the Weibull's shape factor $b$ have been automatically extracted for each test. The results are reported in Figure 17 in comparison to the 2 relationships for the prediction of $b$ at smooth structures proposed by: i) Zanuttigh et al. (2013), where $b$ is a function of the dimensionless average $q$ associated to the single test, $q /\left(g H_{s} T_{m-1}\right)$; ii) Hughes et al. (2012), where $b$ is a function of $R_{d} / H_{s}$.

Figure 17 shows that on average the $b$-values follow the trends of both the formulae. The agreement among values of $b$ and the fitting by Zanuttigh et al. (2013) is characterized by values of $\sigma_{\%}=34 \%$ and $41 \%$ and values of $R^{2}=0.74$ and 0.79 for the UB-exp and UB-num datasets, respectively. The agreement with the formula proposed by Hughes et al. (2012) gives instead $\sigma_{\%}=28 \%$ and $60 \%$ and $R^{2}=0.78$ and 0.71 for UB-exp and UB-num, respectively. Overall, the data from UB-num seem to be better represented by Zanuttigh et al. (2013) while the data from UBexp are in better agreement with Hughes et al. (2012). In Fig. 17-a, the greatest scatter is concentrated around $q_{\text {mean }} /\left(g H_{s} T_{m-1}\right) \approx 6 \cdot 10^{-2} \mathrm{~m}^{3} /(\mathrm{s} \cdot \mathrm{m})$, while in Fig. 17-b a few $b$-values belonging to UB-num are overestimated by Hughes et al. (2012). Overall, both the charts show no heteroscedasticity towards neither $q_{\text {mean }}$ nor $R_{c} / H_{s}$. These results allow the conclusion that the identification step can be successfully adopted for the identification of $V$ and the determination of the shape factor $b$.
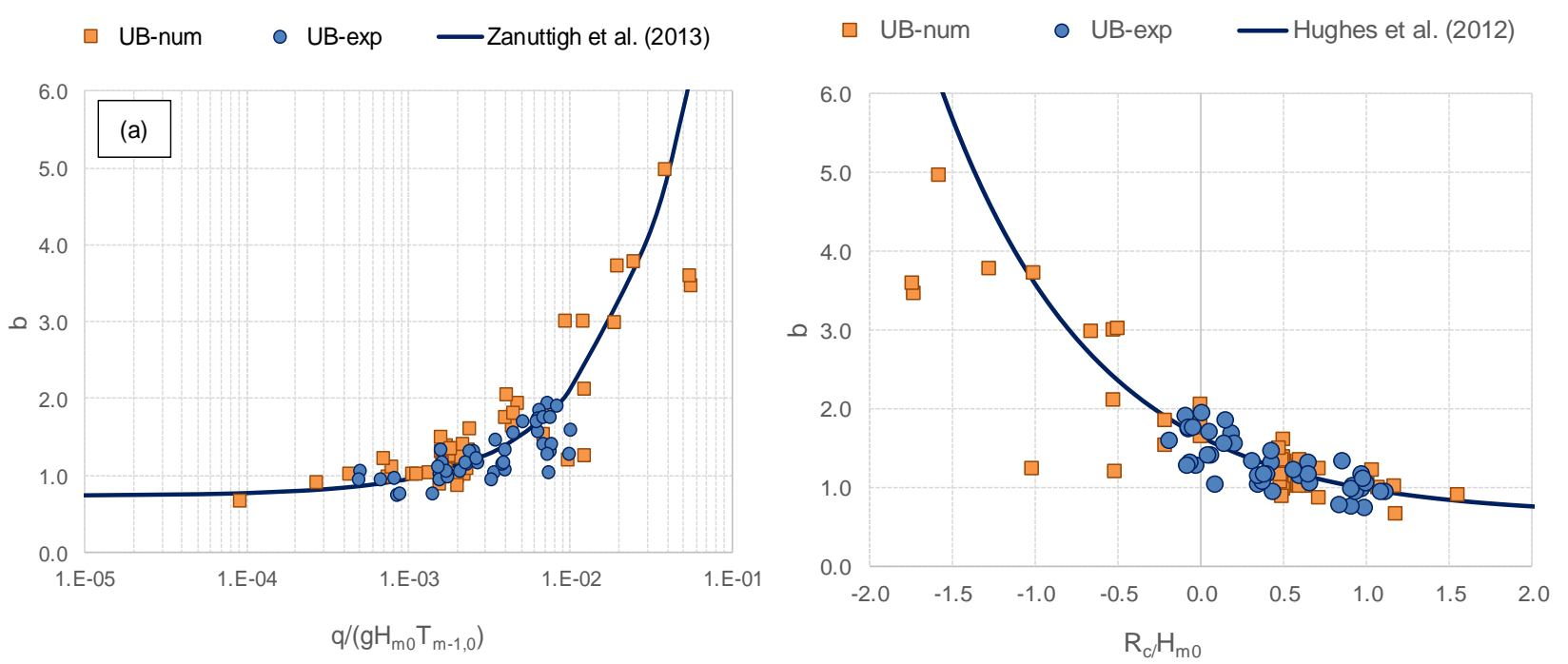

Figure 17 - Values of $b$ derived with the new procedure for UB-num and UB-exp in comparison with the relationships for smooth structures by Zanuttigh et al., 2013 (panel a) and by Hughes et al., 2012 (panel b). 


\section{Application of the new procedure to permeable structures}

816 This Section suggests 2 potential and original applications of the new procedure to the tests on permeable structures by Kramer et al. (2005) (dataset AAU, Sub-section 2.5, Fig. 3 and Table

818 6). The applications allow a detailed description of i) the evolution of the wave shapes along the structure crest (Sub-section 5.1) and ii) the estimate of the percolation rate (Sub-section 5.2).

To this purpose, the procedure was applied to the analysis of the $h$-signals registered at the 2 wgs, wg1 and wg2, placed over the barrier crest at a distance of 0.15 or $0.40 \mathrm{~m}$ (according to the width of the crest itself, see Table 6). From the time-ordered sequences of the coupled overtopping waves, we derived the values of $c, V$ and $q_{c e l}$ from the integration of $c$ by the corresponding $h$.

\subsection{Evolution of the wave shape over the structure crest}

826

The reconstruction of the shape of the overtopping waves at the crest in-shore edge is of practical use for the parametrization of the wave asymmetries (a.o., Peng et al., 2009) and the set-up of physical and conceptual models of wave overtopping propagation, e.g., the Wave Overtopping Simulator (van der Meer et al., 2006) and of wave transmission (Zanuttigh and Martinelli, 2008). Moreover, the study of the evolution of the wave shape may result in important information for the characterization of the flow thickness and velocity over the crest and the landward slope (EurOtop, 2018).

The example of Figure 18 shows a 5-second-time-evolution of the water levels registered at wg1 and wg2 during one of the tests from the dataset AAU at $R_{c}>0$. In this Figure, 4 overtopping events are visible and their correspondence between the 2 wgs is highlighted by the circles, representing the tdc instants filtered and coupled by the procedure.

The single overtopping events can be schematized as triangular volumes (Zanuttigh and Martinelli, 2008) characterized by a duration time $(T d)$ and a rise time $(T r)$, which is the time occurring between the beginning of the event and the instant of the passage of the crest (see Fig. 18). The shape of the overtopping events evolves during the passage from wg1 to wg2 reducing the wave amplitudes heights $(H=Z c r-Z t r)$ and slightly increasing the durations.

The time series of the parameters $T r, T d$ or $H$ can be used to statistically characterize the evolution of the flow over the crest. As an example, Figure 19 illustrates the pdf distribution of the ratio $T r / T d$. The values of $T r / T d$ of each overtopping wave of each test (overall, 21 tests for a total of 6251 overtopping events) are grouped into two histograms in Figure 19, referring to wg1 and wg2. The frequency of the values of $T r / T d>0.5$ is negligible and was cut off from the diagrams.

Figure 18 indicates that the events are highly asymmetric, being the median, the mean and the mode values of the distributions of $T r / T d$ between 0.25 and 0.3 , i.e. significantly lower than 0.5 . The comparison of the 2 diagrams suggests that $T r / T d$ varies with the evolution of the waves over the crest: the distribution at wg 2 tends to be wider (indeed the standard deviation is 0.13 
for wg1 and and 0.17 for wg2) and its mean and median values are slightly higher (respectively 0.30 and 0.29$)$ than at wg $1(0.27$ and 0.26$)$.

854 These results are similar to the findings of the previous study by Zanuttigh and Martinelli (2008). 855 The accuracy achieved with the new coupling procedure, and a wider availability of data, may 856 allow drawing some more general conclusions, leading to a parametrization of the evolution of 857 the shape of the overtopping volumes.
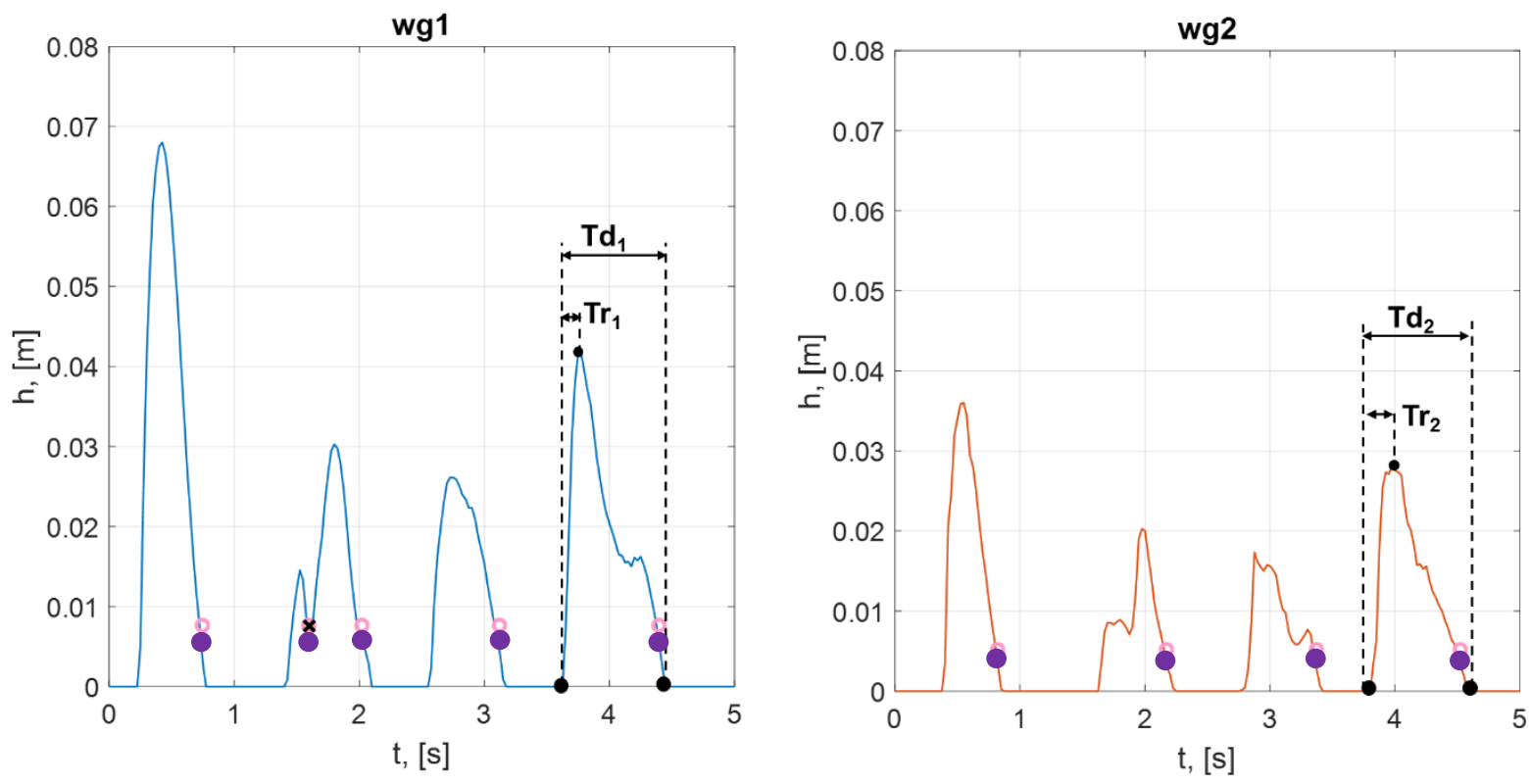

859 Figure 18 - Time evolution of the $h$-signal measured at wg1 and wg2 (to the left and to the right, 860 respectively) for a test at $R_{c}>0$ belonging to the AAU dataset. The durations of the single 861 overtopping events are marked by the circles. The duration time and the rise time ( $T d$ and $T r$, 862 respectively) of the $4^{\text {th }}$ event are highlighted as example.

863
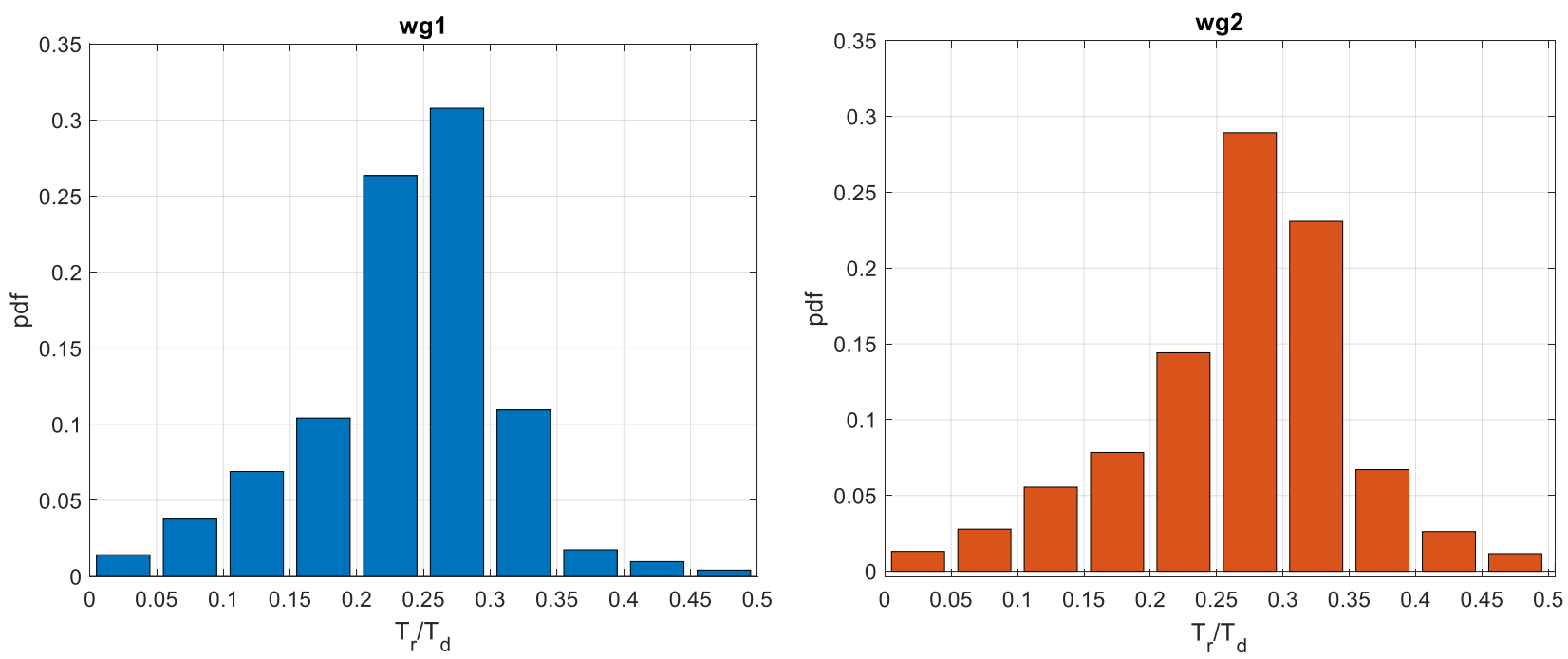

Figure 19 - Histograms of the distributions of the values of the ratio among the rise and the duration times ( $T r / T d$ ) computed at wg1 (a) and at wg2 (b) for each wave identified by the new procedure for the dataset AAU. 


\subsection{Estimate of the percolation over the structure crest}

869

870

871

872

873

874

875

876

877

878

879

880

881

882

883

884

885

886

887

888

889

890

891

892

893

The coupled wave signals resulting from the procedure can be numerically integrated by means of a simple algorithm to derive the individual or total $V$. In case of permeable structures, part of the water volume is lost for percolation into the crest during the passage of the waves from wg 1 to wg2. The percolation rate is an indicator of the dissipation along the crest and could be used for the design of the crest width $G_{c}$. Furthermore, it may represent a key element for the assessment of structural failure scenarios induced by the water infiltration.

Figure 20 reports the percentages of the volumes $V$ lost for percolation over the crest of a permeable structure for the tests composing the dataset AAU. In the Figure, the percentages are grouped by values of $G_{c}$ and are plotted as functions of the dimensionless quantity $\left(R_{u, 2 \%}-R_{c}\right) / H_{s}$. The diagram suggests that, on average, the percentages of the lost $V$ tend to decrease with increasing $\left(R_{u, 2 \%}-R_{c}\right) / H_{s}$ and with decreasing $G_{c}$. Overall, $R_{u, 2 \%}$ appears to be dominant with respect to $G_{c}$. The increase of lost $V$ associated to the wide crest configuration is indeed modest and not systematic. This limited effect of $G_{c}$ on the percolation rate is explained with the overtopping dynamics at $R_{c} \geq 0$ and the observed trend of lost $\mathrm{V}$ with $R_{u, 2 \%}$. The higher $R_{u, 2 \%}$, the farther the wave impinges on the structure crest from the off-shore edge, resulting in a shortening of the percolation area.

Figure 20 shows that percolation rate is never higher than the $60 \%$ (for both the crest configurations) and does not drop below the $25 \%$ in the case of the wide-crest configuration. The single test providing a lost $V$ lower than the $5 \%$ is associated to the smallest and shortest wave $\left(H_{s}=0.027 \mathrm{~m}\right.$ and $T_{p}=0.74 \mathrm{~s}$, check Table 6$)$ which determines in turn the lowest $R_{u, 2 \%}(0.088 \mathrm{~m})$ and one of the lowest values of Pow (7.5\%). The narrow-crest configuration produces, on average, smaller losses of water with respect to the wide-crest configuration for the same value of $\left(R_{u, 2 \%}-R_{c}\right) / H_{s}$. These (few) data indicate that, up to $\left(R_{u^{-}} R_{c}\right) / H_{s} \approx 3$, the percolation rate might be increased roughly $10 \%$ by increasing the crest width on the order of $50-60 \%$.

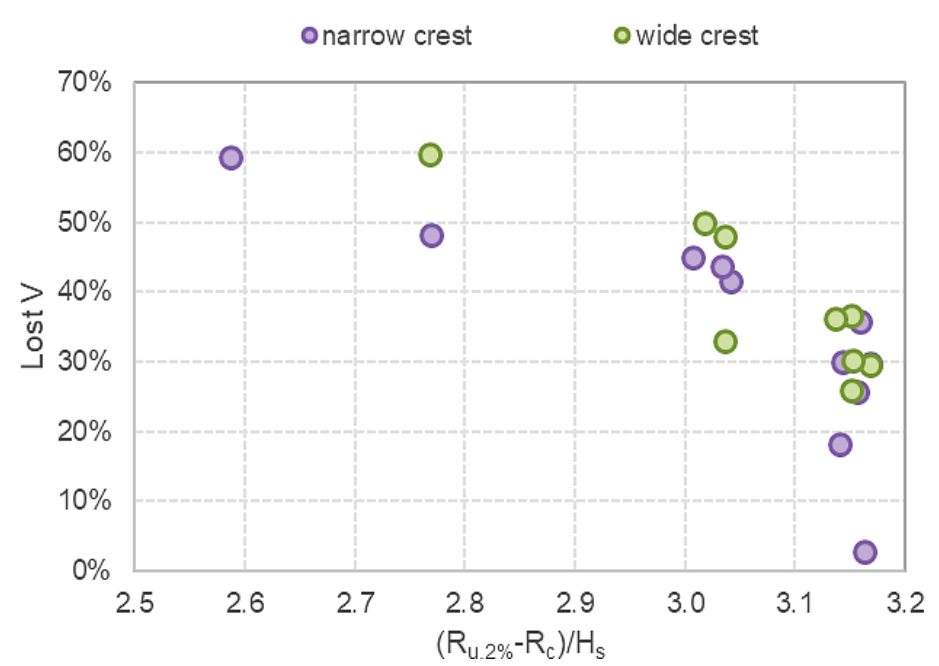

Figure 20 - Percentages of the volumes lost for percolation between wg1 and wg2 (\% Lost $V$ ) as function of the dimensionless wave run-up $\left(R_{u, 2 \%} R_{c}\right) / H_{s}$. Data grouped by values of $G_{c}=0.2$ or $0.6 \mathrm{~m}$, i.e. narrow and wide configuration, respectively. AAU dataset. 


\section{Conclusions}

899 This paper presented a new procedure for the identification and the coupling of the individual

900

901

902

903

904

905

906

907

908

909

910

911

912

913

914

915

916

917

918

919

920

921

922

923

924

925

926

927

928

929

930

931

932

933

934

935

936 wave overtopping events. This procedure has been tested on 5 datasets of new and existing data from the literature, for a total of 192 tests on wave overtopping at smooth dikes (Hughes and Shaw, 2011; Hughes and Thornton, 2016; Formentin and Zanuttigh, 2018 a; Zanuttigh and Formentin, 2018) and permeable structures (Kramer et al., 2005), under perpendicular waves in 2D and 3D conditions, with freeboards $R_{d} / H_{s}$ in the range $[-1,5 ; 1.5]$.

The procedure consists of 2 algorithms, organized into 2 sequential steps, and respectively dedicated to the wave identification and the wave coupling.

The first algorithm takes as input the time signals of the water level recorded at a gauge and identifies the single overtopping waves based on a threshold-down-crossing analysis of the signal. Through the definition of a second threshold value, this algorithm offers the possibility of filtering the wave signal, distinguishing between real overtopping waves and signal noise. Differently from the existing identification algorithms available from the literature, the peculiar introduction of the second threshold allows the user to set his/her own customized level of accuracy in the detection of the waves. The identification step was validated against the data by Hughes and Thornton (2016) resulting in the same accuracy achieved by the authors through the visual examination of the discharge time series. It was also proved that the identification algorithm can be successfully applied to calculate the probability of overtopping of a structure and the reconstruction of the distribution of the extreme overtopping volumes. The results of both the applications are in good agreement with the predictions from the literature formulae, being the relative differences in the range $\pm 15 \%$.

The main novelty of the procedure is represented by the second step algorithm dedicated to the wave coupling. This algorithm elaborates the time-ordered-sequences of the overtopping waves identified by the first step at 2 gauges placed consecutively in the direction of the overtopping flow, and matches each overtopping event propagating between them, driven by the calculation of the minimum and maximum time lags necessary for the propagation. The outputs of the algorithm are the time-ordered-sequences of the coupled overtopping events and the celerity $(c)$ of propagation of each coupled wave. The distance between the gauges and the sampling frequency of the wave signals do affect the accuracy of the wave coupling. In case of flow over the dike crest in breaking or broken wave conditions, the $c$-values obtained with the coupling step resulted very similar to the lab measurements of the flow velocities $(u)$ at the off-shore edge of the levee or dike crest (on average $c / u \approx 0.95$ with a standard deviation $\sigma_{\%}=7.4 \%$ ), in agreement with Schüttrumpf and Oumeraci (2005) and Lykke Andersen et al. (2011). For flow in nonbreaking wave conditions, the values of the time lags necessary to the waves to propagate from one wave gauge to the consecutive one computed with the coupling step were consistent with the time lags obtained by cross-correlating the surface elevation signals $\left(R^{2}=0.88-0.96, \sigma_{\%}=5\right.$ $11 \%)$.

The coupling algorithm allows for a number of original applications such as: 
- The estimation of the overtopping discharges from the integration of the wave celerities. The discharges obtained from the application of the procedure to experimental and numerical data are in good agreement with both the corresponding traditional measurements $\left(R^{2}=0.92\right.$ $\left.0.98, \sigma_{\%}=9.9-34 \%\right)$ and the literature formulae $\left(R^{2}=0.92-0.97, \sigma_{\%}=8.5-35 \%\right)$.

- The evolution of the overtopping characteristics along the structure crest. In this contribution the coupling procedure was specifically applied to investigate the evolution of the wave shape along the crest of rubble mound breakwaters, resulting into a slight decrease of both the wave steepness and the wave asymmetry.

- The estimation of the water percolation rate over the crest of permeable structures. Based on the results of the procedure, it was found that the water percolation rate is mainly determined by the wave run-up and varies between the $25 \%$ and the $60 \%$.

The new procedure is suitable to process 2D wave signals propagating perpendicularly towards the structures. To deal with oblique waves, it would be necessary to calculate the time lags of wave propagation from more than $2 \mathrm{wgs}$, and update the coupling algorithm accordingly (Lykke Andersen et al., 2011).

The limits to the accuracy of the procedure are essentially determined by the definition of the threshold values of the identification step and by the combination of the sample frequency of the input signals and the distance between the gauges for the coupling step. For a proper wave coupling, it is thus recommended to keep the distance between the 2 consecutive wave gauges (diswg) at least equal to 2 or 3 times the time resolution of the instruments themselves (1/sf, with $s f=s a m p l e$ frequency), i.e. $\operatorname{diswg} \geq 2 / s f-3 / s f$.

\section{List of notations}

$\begin{array}{ll}a & \text { Weibull's scale factor } \\ b & \text { Weibull's shape factor } \\ c & \text { Wave (or flow) celerity } \\ c_{2 \%} & \text { Value of } c \text { exceeded by the } 2 \% \text { of the incident waves } \\ c_{d w} & \text { Wave celerity in deep water } \\ c_{s w} & \text { Wave celerity in shallow water } \\ c_{\text {mean }} & \text { Mean of the distribution of the } c \text {-values obtained with the coupling step } \\ c\left(x_{\text {corr }}\right) & \text { Average value of the wave celerity estimated with the cross-correlation of the } h \text { - } \\ & \text { signals at wg1 and wg2 } \\ d i s w g & \text { Distance between two wgs } \\ d t_{\text {max }} & \text { Maximum time lag that may occur between the instant of the tdc of a wave at wg1 and } \\ & \text { at wg2 } \\ d t_{\text {min }} & \text { Minimum time lag that may occur between the instant of the tdc of a wave at wg1 and }\end{array}$




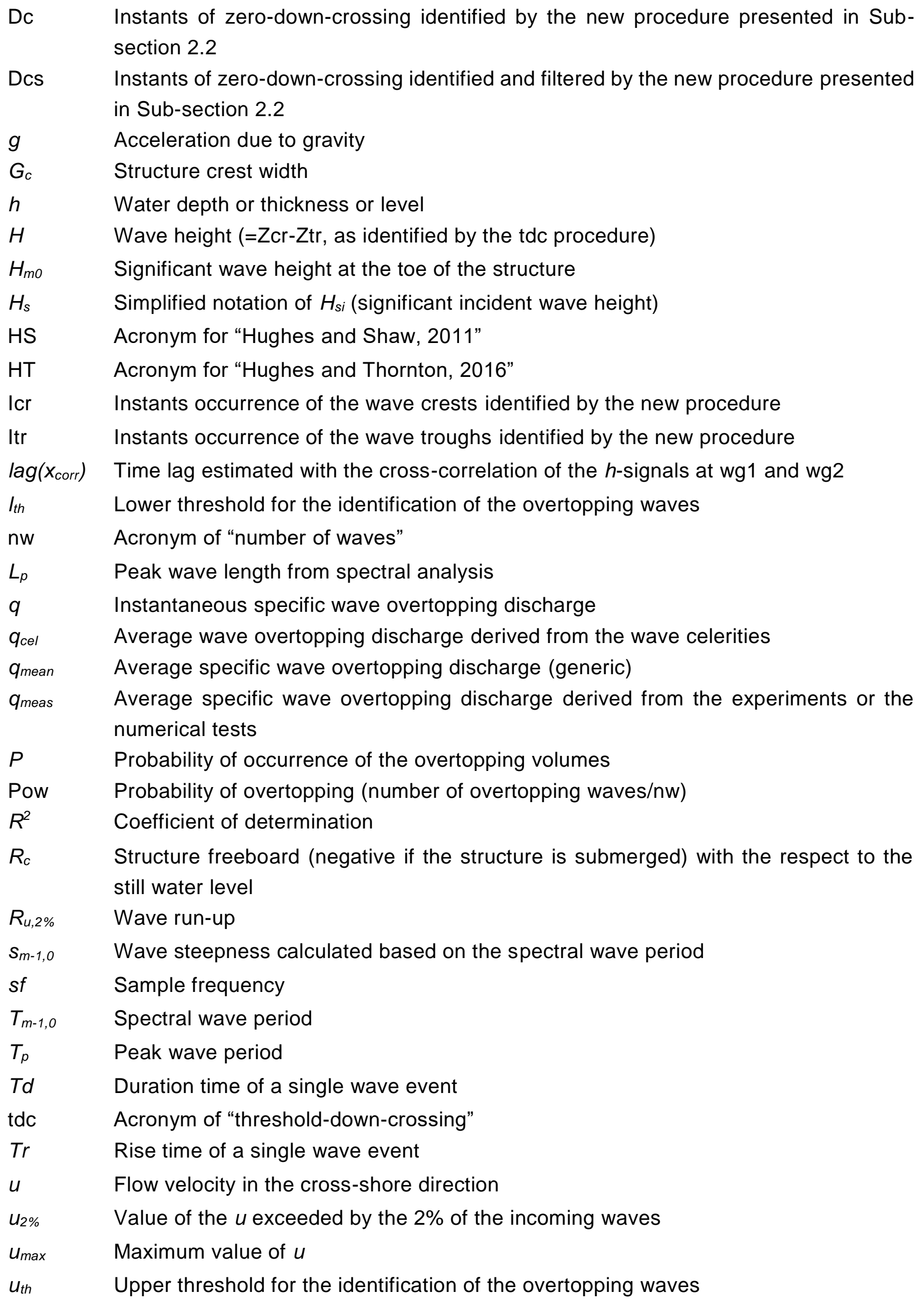




$\begin{array}{ll}V & \text { Overtopping volumes } \\ w g(s) & \text { Acronym of "wave gauge(s)" } \\ w g 1 & \text { Wage gauge 1 (wave gauge at the off-shore edge of the structure crest) } \\ w g 2 & \text { Wage gauge 2 (wave gauge at the in-shore edge of the structure crest) } \\ Z \mathrm{cr} & \text { Wave crest heights identified by the new procedure } \\ Z \mathrm{tr} & \text { Wave trough heights identified by the new procedure } \\ \alpha_{i n} & \text { In-shore slope of a structure } \\ \alpha_{o f f} & \text { Off-shore slope of a structure } \\ \xi_{m-1,0} & \text { Iribarren-Battjes breaker parameter } \\ \sigma_{\%} & \text { Standard deviation }\end{array}$

\section{Acknowledgments}

961 The authors would like to express their sincere gratitude to Professor S.A. Hughes for providing 962 his own experimental data and his analyzed results using FlowDike data for the validation of the 963 procedure.

964 The support of the European Commission through Contract 244104 THESEUS ("Innovative 965 technologies for safer European coasts in a changing climate"), FP7.2009-1 Large Integrated 966 Project, is also gratefully acknowledged for funding the whole $\mathrm{PhD}$ of the first author and this 967 activity specifically.

\section{References}

970 Bosman, G, Van der Meer, J.W., Hoffmans,G., Schüttrumpf, H. and Verhagen., H.J., 2008. 971 Individual overtopping events at dikes. ASCE, proc. ICCE 2008, Hamburg, Germany, p. 29449722956.

973 Chella, M. A., Bihs, H. and Myrhaug, D., 2015. Characteristics and profile asymmetry properties 974 of waves breaking over an impermeable submerged reef, Coastal Engineering, 100, 26-36.

975 Denny, M.W., 1988. Biology and the mechanics of the wave-swept environment. Princeton 976 University Press, Princeton.

977 EurOtop, 2018. Manual on wave overtopping of sea defences and related Structures. An 978 overtopping manual largely based on European research, but for worldwide application. N.W.H. 979 Allsop, T. Bruce, J. DeRouck, A. Kortenhaus, T. Pullen, H. Schüttrumpf, P. Troch, J.W. van der 980 Meer and B. Zanuttigh. www.overtopping-manual.com 
981 Formentin, S.M., Zanuttigh, B., van der Meer, J.W. and Lara, J.L., 2014. Overtopping flow characteristics at emerged and over-washed dikes, Proc. of XXXIV International Conference on 983 Coastal Engineering, Seoul (ROK).

984 Formentin, S.M. and Zanuttigh, B., 2018 (a). A new method to estimate the overtopping and 985 overflow discharge at over-washed and breached dikes, Coastal Engineering, 140, pp. 240-256.

Formentin, S.M. and Zanuttigh, B., 2018 (b). A new fully-automatic procedure for the identification and the coupling of the overtopping waves, Proc. of XXXVI International Conference on Coastal Engineering, Baltimore (MD).

Franco, L., Geeraerts, J., Briganti, R., Willems, M., Bellotti, G., De Rouck, J., 2009. Prototype measurements and small-scale model tests of wave overtopping at shallow rubble mound breakwaters: the Ostia-Rome yacht harbour case, Coastal Engineering 56, 154-165.

Hughes, S.A., 2008. Combined wave and surge overtopping of levees: Flow hydrodynamics and articulated concrete mat stability, Technical Report No. ERDC7CHL TR-08-10, US Army Engineer Research and Development Center, Vicksburg, MS.

Hughes, S.A., Thornton, C.I., van der Meer, J.W. and Scholl, B., 2012. Improvements in describing wave overtopping processes. ASCE, Proc. of XXXIII ICCE, Santander, Spain.

Hughes, S.A., 2015. Hydraulic Parameters of Individual Overtopping Wave Volumes, Technical Report. Engineering Research Center, Colorado State University, Fort Collins, CO (68pp).

Hughes, S.A. and Thornton, C.I., 2016. Estimation of time-varying discharge and cumulative volume in individual overtopping waves, Coastal Engineering, 117, 191-204.

Kramer, M., Zanuttigh, B., van der Meer J. W., Vidal, C. and Gironella, X., 2005. Laboratory experiments on low-crested structures, Coastal Engineering, 52, 867-88.

Lara, J.L., Ruju, A. and Losada, I.J., 2011. Reynolds Averaged Navier-Stokes modelling of long waves induced by a transient wave group on a beach. Proceedings of the Royal Society A, vol. 467, 1215-1242.

Lorke, S., Brüning, A., Bornschein, A., Gilli, S., Krüger, N., Schüttrumpf, H., Pohl, R., Spano, M., Werk, S., 2009. Influence of wind and current on wave run-up and wave overtopping. Hydralab - FlowDike, Report 2009 (100pp).

Lorke, S., Brüning, A., Van der Meer, J., Schüttrumpf, H., Bornschein, A., Gilli, S., Pohl, R., Spano, M., Řiha, J., Werk, S., Schlütter, F., 2010. On the effect of current on wave run-up and wave overtopping. Proceedings of XXXII ICCE, Shanghai, China. American Society of Civil Engineers, New York.

Losada I.J, lara J.L., Christensen E.D. and Garcia N., 2005. Modelling of velocity and turbulence fields around and within low-crested rubble-mound breakwaters, Coastal Engineering 52, pp. 887-913. 
1016 Lykke Andersen, T., Nørgaard, J. H. and Burcharth, H.F., 2011. A Method for Determination of 1017 Run-Up Front Velocities on Dikes in Oblique and Short-Crested Waves. Proceedings of Coastal 1018 Structures 2011, Yokohama, Japan, pp. 588-598.

1019 Molines J., Herrera M.P., Gomez-Martin M.E., Medina J.R., 2019. Distribution of individual wave 1020 overtopping volumes on mound breakwaters, Coastal Engineering 149, 15-27.

1021 Nørgaard J.Q.H, Lykke Andersen, T. and Burcharth H.F., 2014. Distribution of individual wave 1022 overtopping volumes in shallow water wave conditions, Coastal Engineering 83, 15-23.

1023 Peng Z., Zou Q., Reeve D. and Wang B., 2009. Parametrization and transformation of wave 1024 asymmetries over a low-crested breakwater, Coastal Engineering, 59, 1123-1132.

1025 1026

1027 1028

1029 1030

1031 1032 1033 1034 1035 1036 1037

1038 1039

1040 1041 1042

1043 1044 1045

Platteeuw, J., 2015. Analysis of individual wave overtopping volumes for steep low crested coastal structures in deep water. Phd, UGent, Zwijnaarde; Belgium.

Schüttrumpf, H.F.R. 2001. Wellenüberlaufströmung bei See-deichen, Ph.D.-thesis, Technical University Braunschweig.

Schüttrumpf, H.F.R. and Oumeraci, H., 2005. Layer thicknesses and velocities of wave overtopping flow at sea dikes, Coastal Engineering, 52 (6), 473-495.

Van der Meer, J.W. and Janssen, J.P.F.M., 1994. Wave run-up and wave overtopping at dikes and revetments. Delft Hydraulics.

Van der Meer, J.W., Bernardini, P., Snijders,W., E. Regeling. 2006. The wave overtopping simulator. Proceedings of XXX ICCE, vol. 5. World Scientific, 4654-4666.

Van der Meer, J.W., B. Hardeman, G.J. Steendam, H. Schüttrumpf and H. Verheij, 2010. Flow depths and velocities at crest and inner slope of a dike, in theory and with the Wave Overtopping Simulator. ASCE, Proc. XXXII ICCE, Shanghai, China.

Van Gent, M.R., 2002. Wave overtopping events at dikes. Proceedings of the 28th International Coastal Engineering Conference, vol. 2. World Scientific, 2203-2215.

Victor, L., 2012. Optimization of the Hydrodynamic Performance of Overtopping Wave Energy Converters: Experimental Study of Optimal Geometry and Probability Distribution of Overtopping Volumes. Phd, UGent, Zwijnaarde; Belgium.

Zanuttigh, B and Lamberti, A., 2006. Experimental analysis and numerical simulations of waves and current flows around low-crested rubble-mound structures, Journal of Waterway, Port, Coastal, and Ocean Engineering, 132(1), 10-27.

Zanuttigh B.; Martinelli L., 2008. Transmission of wave energy at permeable low-crested structures, Coastal Engineering, 55 (12), 1135 - 1147.

Zanuttigh, B., Martinelli L. and Lamberti A., 2008. Wave overtopping and piling-up at permeable low crested structures, Coastal Engineering 55, 484-498. 
1050 Zanuttigh, B., van der Meer, J.W., Bruce, T. and Hughes, S. 2013. Statistical characterisation of 1051 extreme overtopping wave volumes. Proc ICE, Coasts, Marine Structures and Breakwaters 2013, 1052 Edinburgh, UK.

1053 Zanuttigh B. and Formentin S.M, 2018. Reduction of the wave overtopping discharge at dikes in 1054 presence of crown walls with bullnoses, Proceedings of the XXXVI International Conference on 1055 Coastal Engineering, Baltimore (MD).

1056 